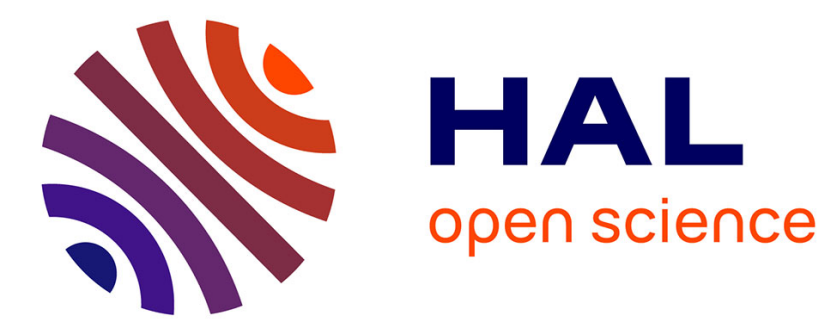

\title{
Analysis of combustion modes in a cavity based scramjet
} Jiangheng Ruan, Pascale Domingo, Guillaume Ribert

\section{To cite this version:}

Jiangheng Ruan, Pascale Domingo, Guillaume Ribert. Analysis of combustion modes in a cavity based scramjet. Combustion and Flame, 2020, 215, pp.238-251. 10.1016/j.combustflame.2020.01.034 . hal02559646

HAL Id: hal-02559646

https://hal-normandie-univ.archives-ouvertes.fr/hal-02559646

Submitted on 4 Dec 2020

HAL is a multi-disciplinary open access archive for the deposit and dissemination of scientific research documents, whether they are published or not. The documents may come from teaching and research institutions in France or abroad, or from public or private research centers.
L'archive ouverte pluridisciplinaire HAL, est destinée au dépôt et à la diffusion de documents scientifiques de niveau recherche, publiés ou non, émanant des établissements d'enseignement et de recherche français ou étrangers, des laboratoires publics ou privés. 


\title{
Analysis of combustion modes in a cavity based scramjet
}

\author{
Jiangheng L. Ruan, Pascale Domingo*, Guillaume Ribert \\ CORIA - CNRS, Normandie Université, INSA de Rouen, Technopole du Madrillet, BP 8 \\ 76801 Saint-Etienne-du-Rouvray, France
}

\begin{abstract}
Large eddy simulations (LES) of non reactive and reactive flows in a cavity-based scramjet combustor configuration from the U.S Air Force Research Laboratory (AFRL) are performed. These simulations feature a 22 species and 206 reactions chemical scheme for ethylene/air. The ability of LES to reproduce the main features found in the experiment is first emphasised such as the average velocity field and the stability of the combustion for the case studied. The influence of the mesh resolution and of the thermal wall condition on the simulation results is also investigated along with the soundness of the use of a laminar model for the filtered source terms. The results of the simulations with the finest grid (resolution of 100 micrometers in the flame region) are then employed to gain understanding in the flame dynamics. This reactive simulation shows the persistence of the two recirculation zones already present in the non reactive flow. The globally high temperature into the cavity helps to sustain a reactive zone located in the mixing layer above the cavity. Combustion first occurs in a diffusion dominated regime followed by the efficient burning of a well stirred mixture (rich then lean). A significant diffusion dominated burning is also found inside the cavity. The links between the residence time inside the cavity and the efficiency of the combustion are explored along with the velocity/heat release correlation.
\end{abstract}

Keywords: Turbulent supersonic combustion, Combustion regimes, Large Eddy Simulation, Residence time, Flame Stabilisation

\footnotetext{
${ }^{*}$ Corresponding author:

Email address: domingo@coria.fr (Pascale Domingo)
} 


\section{Introduction}

The last decades have been marked by great progress in hypersonic technologies. The supersonic combustion ramjet (scramjet) has been identified as a valuable design able to cope with these hypersonic speeds. Indeed, the main problem to overcome is the short residence time of the fuel in the combustion chamber. This time being of the order of a millisecond, mixing and combustion cannot operate efficiently making the flame holding a challenging task. The cavity-based scramjet has been therefore considered as a promising solution because the recirculation of the combustion gases promotes the mixing and the burning of the reactants on a very short distance. The performance of this configuration depends on the choice of the geometric parameters of the cavity and fuel injection area, essential point for an efficient combustion.

Predictive tools capable of reproducing the complexity of this flow, which combines highly compressible turbulent flows with finite rate chemistry effects, are necessary for the development of future scramjets. A recent detailed review of the challenges encountered in the modeling of highspeed combustion is found in the paper from from Gonzalez-Ruez et al. [1]. However, the existing literature is still scarce or restricted, and the vast majority of computational works in cavity-based scramjet were performed in Reynolds-averaged Navier-Stokes (RANS) framework. Due to the increase in high performance computing, the use of Large-Eddy Simulation (LES) for supersonic combustion is now becoming more and more relevant. Large Eddy Simulations of configurations featuring combustion stabilized by a cavity at high speed have been recently achieved by Saghafian et al. [2] and Lacaze et al. [3] for the HIFiRE test-bench, by Wang et al. [4] for their own experiment and also by Hassan et al. [5] for the US Air Force Research Laboratory (AFRL) facility [6]. The objectives of the present study are twofold: first, to contribute at the assessment of the ability of the LES technique to predict highly compressible multi-species reacting flows; and second, provide some insight on the behaviour of the reacting zones in a cavity-based scramjet. This last point will be an opportunity to propose new analytical tools within the framework of the LES for highly compressible flows. As in the work from Hassan et al. [5], the facility from AFRL will support this goal. 
The paper first describes the numerical set-up and as a first step, the validation on available velocity measurements are presented. The impact of the prescribed wall temperature is briefly discussed, along with the possible impact of the number of injectors retained in the simulation. The no-model approach used in the simulations for the estimation of the filtered source terms which neglects subgrid fluctuations of species concentration and temperature, is discussed in details. A thorough analysis of the preferential combustion conditions in term of velocity, flame regimes and residence time, is then performed.

\section{Configuration and numerical set-up}

\subsection{Configuration description}

Among the experimental configurations available in the literature [7-11], that of AFRL is chosen because a large number of experiments have been carried out with this device over the years. In particular, Tuttle et al. [6] recently used particle image velocimetry to measure velocity and vorticity fields for non-reactive and reactive cavity with different fuel flow rates and Do et al. [12] have provided an estimation of ethylene concentration. In the experimental set-up, the air flow is accelerated through a nozzle to reach supersonic speed and enters the isolator at nominal Mach 2, with a total temperature and pressure of $589 \mathrm{~K}$ and $483 \mathrm{kPa}$, respectively. The air flow then meets the fuel (ethylene) inside the cavity where combustion has been shown to take place. Ethylene $\left(\mathrm{C}_{2} \mathrm{H}_{4}\right)$ is injected at $310 \mathrm{~K}$ which makes the auto-ignition impossible, spark plugs are then used to force ignition.

The wind tunnel has an isolator $177.8 \mathrm{~mm}$ long with a constant area section $H \times W=50.8 \times$ $152.4 \mathrm{~mm}^{2}$. At the exit of the isolator, the lower wall of the duct is diverging by an angle $\alpha=2.5^{\circ}$. The cavity is located at $76.2 \mathrm{~mm}$ further from the start of the diverging section. The aft wall of the cavity is slanted by $\theta=22.5^{\circ}$ to avoid oscillations of acoustic waves inside the cavity. Its length and depth are respectively $L=66 \mathrm{~mm}$ (length of floor of the cavity plus $0.5 \mathrm{D} / \tan (\theta)$ ) and $D=16.5 \mathrm{~mm}$. An array of 11 fuel injection ports of diameter $d=1.6 \mathrm{~mm}$ are evenly distributed on the aft cavity wall. at $y=-19.57 \mathrm{~mm}$. A sketch of the experimental set-up can be found 
in figure 1 .

\subsection{Numerical set-up}

The CORIA inhouse code, SiTCom-B [13-17], is used for the computations. SiTCom-B is a fully compressible structured code working with cartesian grids, based on an explicit Finite Volumes (FV) scheme, and has already shown its capability to predict supersonic combustion flows [18, 19]. As cartesian grids can only describe rectangular shape geometries, Immersed Boundary Method (IBM) is implemented [18, 20] to handle the experimental configuration which features a cavity and ethylene injection device. The code has a fourth-order centered skewsymmetric-like scheme for the convective terms and a fourth-order centered scheme for the diffusive terms. A fourth-order Runge-Kutta method is applied for the time integration. Besides, second and fourth-order artificial dissipation terms of Swanson et al. [21] are implemented to overcome spurious oscillations and damp high-frequency modes. Unsolved subgrid-scale fluxes are modeled by the Germano closure [22]. Subgrid Prandtl and Schmidt numbers are set to 0.9. Mixture diffusion coefficients for each species [23] are considered based on binary diffusion coefficients [24]. A correction [25] is applied to the diffusive fluxes in order to strictly enforce mass conservation. Mixture averaged viscosity [23, 26] and conductivity [27] are also employed. The 3D Navier Stokes Characteristic Boundary Conditions (NSCBC) are applied to describe the air and fuel inflows. The outflow of the computational domain is using a zero-gradient condition. The upper and lower walls of the scramjet are modelled either with an adiabatic non-slip condition or with a mixed adiabatic/fixed temperature non-slip condition following the approach from Baurle [28]. For this latter wall condition, adiabaticity is enforced if the wall temperature is below $800 \mathrm{~K}$, but set to $800 \mathrm{~K}$ if the wall temperature reaches $800 \mathrm{~K}$. The adiabatic condition can lead to very high temperature levels at the cavity wall which are a priori not observed in the experiment. The impact of this simplified wall condition will then be assessed by comparison with the results with the mixed wall condition. The side sections use periodic conditions since only one or two injectors will be considered. The width of the domain $12.7 \mathrm{~mm}$ for one injector and $25.4 \mathrm{~mm}$ for two injectors. For the case with a single injector, this latter is centered at the middle plane of the 


\begin{tabular}{c|cccc}
\hline \hline Mesh & $\Delta \mathrm{x}(\mu \mathrm{m})$ & $\Delta \mathrm{y}(\mu \mathrm{m})$ & $\Delta \mathrm{z}(\mu \mathrm{m})$ & Cells \\
\hline Fine & 100 & $80-150$ & $100-150$ & $300 \mathrm{M}$ \\
Coarse & 200 & $150-200$ & $160-300$ & $45 \mathrm{M}$ \\
\hline \hline
\end{tabular}

Table 1: Description of the two meshes used for computations. The number of cells is given for one injector. $\mathrm{M} \equiv 10^{6}$.

computational domain.

The nozzle is not computed and the simulation starts at the beginning of the isolator. The origin is located at the inlet of the computational domain, on the bottom wall. The axial velocity profile prescribed at inlet follows the relation: $U=1.22 U_{0}(y / H)^{1 / 7}(1-y / H)^{1 / 7}$ with $U_{0}$ set to $727 \mathrm{~m} / \mathrm{s}$ and corresponding to a Mach number of 2 . Turbulence in injected at the inlet to trigger the boundary layer development with an intensity of $10 \%$ of the local axial velocity and distributed evenly on the three components of the velocity. Several tests [29] have been performed to calibrate the inlet profiles as well as the intensity of turbulence injected. A weak sensitivity of the velocity profiles in the cavity vicinity to these parameters has been found, due probably to the long distance between the inlet and the cavity corner $(254 \mathrm{~mm})$ and also to the predominant role of the shear layer above the cavity in the turbulence development. The computational domain is extended $81 \mathrm{~mm}$ after the cavity (see Fig. 11). The injection of ethylene at the cavity bottom is done in the computational set-up (Fig. 11) through round pipes (diameter $1.6 \mathrm{~mm}$ ). Each of these pipes delivers a mass flow rate of ethylene corresponding to one eleventh of the total mass flow rate of ethylene prescribed. Their inlets are located at the same plane than the outlet of the nozzle $(x=400 \mathrm{~mm})$. These pipes connect with the cavity aft wall at the locations indicated in the paper from Tuttle et al. [6].

Two mesh resolutions denoted "Fine" and "Coarse" are used with respectively 300 and 45 millions of cells when only one injector is included (see Tab. 11). The coarser mesh is used to describe the case with two injectors (90 millions of cells in total). The cell size is kept constant in $x$-direction, refined close to the wall and the mixing layer above the cavity in $y$-direction as well as close to the injector in $y$ - and $z$-direction. The number of cells to describe the diameter of the injector is then 16 for the fine mesh and 10 for the coarse mesh. A zoom of the coarse mesh in the cavity region, taken in a plane cutting one injector is presented in Fig. 2. The geometry where 
immersed boundary conditions are enforced is plotted in white.

The dimensionless wall distance $y^{+}$computed at the upper wall and the bottom wall of the simulation domain is plotted in Fig. 3 for a case without chemical reaction. This value being on average 10 for the fine mesh and 18 for the coarser one at the upper wall and at the bottom wall, excepted in the cavity area, the use of a wall-law model is found necessary. The zero-equation mixing length model based on the van Driest damping function [30] has been added to compensate for this lack of resolution in the wall region. In the cavity area (from $x=0.255 \mathrm{~m}$ to $x=0.33 \mathrm{~m}$ ), the mesh resolution being sufficient to capture the boundary layer, the wall-model is switched off.

\section{Non-reacting flow simulations}

The simulation of the non-reactive case is first addressed and no fuel is injected as in the experiment (case 0 in the work of Tuttle et al. [6] ).

\subsection{Flow description}

Averaged streamlines of the non-reactive flow are shown in Fig. 4 for the fine mesh. As discussed in previous works [31, 32], the velocity disparity between the supersonic air flow and the one inside the cavity creates a clockwise large recirculation area, which is responsible of the mass exchange at the shear layer. This recirculation zone is the main feature of flame stabilization by a cavity, as it is intended to trap the hot combustion products to maintain the cavity at high temperature thus insuring pre-heating and ignition of the fresh reactants. The primary recirculation zone is at high speeds, approaching Mach 0.5. A much smaller secondary anti-clockwise recirculation area is found at the front of the cavity with lower speed. The shape of the recirculation areas is similar to the one found in the work of Baurle [28], and the velocity of the primary recirculation zone is very close to the experimental data of Tuttle et al. [6]. A variety of averaged flow properties for non-reactive case are displayed in Fig. 5 for the fine mesh. The Mach number inside the cavity is kept low, approaching 0 at the cavity front, and is under 0.5 in the large recirculation area. The whole cavity is then at subsonic speeds. A strong reattachment shock system where the pressure reaches $90 \mathrm{kPa}$ is identified at the aft wall of the cavity. This system of shocks is also present 
at the same position in the RANS/LES performed by Baurle [28]. This shock system is actually responsible of the temperature increase inside the cavity as the temperature rise which is initiated at the base of the shock structure, is brought to the front and the middle of the cavity due to the recirculation effect. There is also a small preheating due to the frictions with the wall upstream the cavity. All these heatings lead to an average temperature of $450 \mathrm{~K}$ in the cavity, which is $120 \mathrm{~K}$ higher than the freestream. The pressure inside the cavity is heterogeneous, varying from 40 to 90 $\mathrm{kPa}$.

\subsection{Comparison with experimental results}

Comparisons between results obtained with coarse and fine meshes and the experimental data have been performed with one injector and also with two injectors for the coarse mesh. Statistics are gathered for $6 \mathrm{~ms}$ physical time for the coarse mesh and $2 \mathrm{~ms}$ for the fine mesh at eight locations inside the cavity (see Fig. 6 where distances are expressed from the upstream cavity corner). The residence time in the cavity can be estimated empirically [33] around $0.9 \mathrm{~ms}$. Then, sampling over $2 \mathrm{~ms}$ might be too short and is a pragmatic choice considering the cpu cost of the simulations performed with the fine grid. The figure 7 shows the streamwise and transverse velocity profiles. No significant differences are found between the simulations featuring one or two injectors excepted for the transverse velocity at the two last positions. These differences might have arisen from the influence of the lateral domain width on the development of the turbulence which is then found of low order. The experiment is fairly well predicted by both meshes for the streamwise velocity except at the front of the cavity where the mixing layer is not well captured. The fine mesh provides a slightly better fit of the streamwise velocity especially at positions $20 \mathrm{~mm}$ and $30 \mathrm{~mm}$ where the description of the mixing is improved by the increase in spatial resolution. On the opposite, the transverse velocity is better described by the coarse mesh which could be explained by the longer time sampling. Until the middle of the cavity, the simulations stays close to the experiment, but is out of phase when reaching the rear of the cavity. This discrepancy might be due to the reattachment shock system which is either imperfectly predicted by the simulation or 
would need a longer sampling time. Considering the difficulties attached to velocity measurements in a cavity, one can considered that a reasonable agreement between simulations and experiment is reached and that the two mesh resolutions retained are acceptable. Since only minor differences are evidenced between the simulations with one or two injectors, only geometries with one injector will be retained in the rest of the paper for the analysis of the combustion modes.Nevertheless, one have to keep in mind that the lateral walls are not included in the present work where simplified periodic boundary conditions are imposed. This constraint might have a significant impact on the flow behavior but will not be investigated in the present study. A comparison on the wall-pressure has also been performed. The simulations underestimate the pressure in the cavity by around $10 \%$ (see Fig. 8). While in the experiment the wall-pressure is found higher in the cavity than in the area before the cavity [6], in the simulations, the wall-pressure is constant from the region before the cavity to the cavity aft wall and then increase due to the shock. It should be noted, that the evolution of the wall pressure found in our simulation is in line with previous measurements from Gruber et al. [31] for cavities with a similar shape.

\section{Validation of the reactive simulations}

Ethylene is injected at a fuel flow rate of 99 Standard Liters Per Minute (SLPM) as in the case 3 of the work of Tuttle et al. [6]. The simulations are performed by computing the Arrhenius laws and energy heat release directly from the transported values of temperature and mass fractions, i.e. without accounting for potential subgrid scale effects. A reduced kinetic scheme of 22 species and 206 reactions [34] for ethylene is used as retained in the simulations from Baurle [28].

As for the experiment, the local conditions of temperature and pressure cannot allow auto-ignition of ethylene. To start the combustion and mimic the ignition device, a spheric hot source term ( $4 \mathrm{~mm}$ of diameter) has been added to the energy equation and positioned at the exit of the injector locally increasing the temperature up to $1800 \mathrm{~K}$ for $1 \mathrm{~ms}$. After stopping the forcing in the energy equation, the simulation is run for $10 \mathrm{~ms}$ to evacuate nonphysical ignition phenomena. At this fuel loading condition, the combustion is well stabilized in the cavity as found in the experiment [6]. 


\subsection{Flow description}

An instantaneous field of the $Q$-criterion colored by CO concentration is shown in Fig. 9 , Instantaneous heat release rate, temperature and major species mixture fractions are shown in Fig. 10 for a plane between two injectors corresponding to one side of the computational domain because the computational domain contains only one injector. The mixing layer above the cavity as well as the flow over the ramp display high turbulence level while the front of the cavity is more quiet due to the lower velocities and high temperature encountered. The most reactive zones are located in the mixing layer and into the cavity between the main and secondary recirculation zones. The isoline Mach = 1 indicates that combustion occurs preferentially at subsonic speeds, discussed in section 5.2.1. The temperature distribution inside the cavity can be roughly split in three regions with nearly homogeneous distribution: (i) zone over $2000 \mathrm{~K}$ corresponding to the primary recirculation (yellow color on the temperature field in Fig. 10), (ii) zone around $1400 \mathrm{~K}$ corresponding to the primary recirculation (carmine red) and (iii) zone around $1000 \mathrm{~K}$ (blue) stuck between the isosurface Mach = 1 and the zones (i) and (ii).

The mixture fraction is computed with Bilger et al.'s formulation [35] and the cavity is found globally very rich (the stoichiometric mixture is $Z_{s t}=0.06366$ ). The small recirculation area at the front of the cavity is only filled with fuel and burnt gases, and no oxygen left. Combustion cannot occur in this area because of the absence of oxygen. At the top of the small recirculation zone, ethylene, heated by burnt gases to $1500 \mathrm{~K}$, is carried away by the airflow to the mixing layer between the large recirculation area and the freestream, and reacts in that region providing energy to heat the airflow entering at the rear of the cavity. Then, the heated airflow reacts with a small part of cold fuel from the injector to form burnt gases that will heat the remaining cold fuel, and the circle is complete. Ethylene entering the large recirculation area reacts immediately with air available in that region due to preheating by burnt gases, so the mass fraction of ethylene is almost zero. This reaction maintains a very high temperature in the large recirculation zone leading to a stable flame.

Note that in the experiments of Tuttle et al. [6] additional fuel flow rate $\left(\dot{m}_{F}\right)$ are available. In par- 
ticular decreasing $\dot{m}_{F}$ leads to a flame less and less stable which disappears when $\dot{m}_{F}=36$ SLPM. Such a behavior has been recovered by our simulations [29], but will not be developed in the present article.

\subsection{Velocity and pressure fields}

Comparisons on time-averaged wall pressure and velocities are shown in Fig. 11. Once the combustion is established and stabilized, statistics have been extracted during $2 \mathrm{~ms}$ to be compared to the experimental data. For this reactive case, the LES captures precisely the wall pressure upstream of the cavity and at its bottom but an overestimation appears near the ramp. The evolution of the pressure is similar to what is obtained by Hassan et al. [5] for a case with a lower fuel flow rate (56 SLPM): a pressure field globally homogeneous in the cavity with an important increase beginning at the middle of the ramp. In Fig. 12, the mean streamwise velocity is fairly well predicted. As for the non reactive case, the mixing after the cavity corner is less developed in the simulation. The spanwise velocity prediction is less reliable especially for the last position located on the cavity ramp. This result could be linked to the over prediction of the pressure at the same location. The same quality of agreement is reached by Hassan et al. [5]. In their work, an hybrid RANS/LES approach is used with a mesh resolution insuring that the first cell is within one wall unit and a well developed inflow condition has been implemented. Despite the difference in numerics, turbulence forcing at the inlet and mesh resolution between Hassan's study and the current one, the same tendencies are found in both sets of simulations, i.e. an imperfect description of the mixing layer thickness just after the cavity corner, a stronger recirculation in the simulations and an imperfect reproduction of the streamwise velocity. Even if the case simulated by Hassan et al. [5] has a fuel flow rate almost twice less than the one considered in this study, the differences in experimental velocity profiles are rather small. The reason of the disagreement between experiment and simulations remains to be found and several hypothesis can be advanced such as the size of computational the domain after the cavity, experimental measurements uncertainties or the strongly asymmetric shape of the nozzle upstream of the throat which may influence the velocity profiles until the cavity. 


\subsection{Impact of the wall thermal condition}

In order to quantify the impact of wall temperature on the flow, a simulation with quasiisothermal wall condition has been performed with the fine mesh resolution. The quasi-isothermal wall condition is actually a combination of a real isothermal and an adiabatic wall condition. The walls become isothermal only when the wall temperature exceed $800 \mathrm{~K}$, otherwise they are considered adiabatic. This implementation of mixed wall conditions is similar to the one employed by Baurle [28] for his RANS simulations. Averaged temperature profiles in the injector centerplane at different locations are displayed Fig. 13(a), As expected, a fixed low wall temperature leads to a globally cooler mixture than with the adiabatic conditions. However, the same tendency are recovered and no influence on the combustion stability is found. This weak influence is retrieved on the averaged axial velocity profiles which are very found nearly identical whatever the wall condition (see Fig. 13(b)). We acknowledge that a simulation included the experimental heat flux or tem-

perature distributions at the wall would avoid any ambiguity, however since no experimental data is available concerning these quantity and since rather small differences have been found between the adiabatic and the mixed adiabatic/fixed wall temperature simulations, the analysis proposed in the following section will be based only on the simulations making use of the simplified adiabatic wall condition.

\section{Analysis}

\subsection{A posteriori validation of the no-model approach}

The simulations were performed using the laminar flame model, or no-model for reaction rates, which relies on the assumption: $\tilde{\dot{\omega}}_{k}(\rho, \underline{Y}, T) \approx \dot{\omega}_{k}(\bar{\rho}, \underline{\tilde{Y}}, \tilde{T})$. While this approach is often retained in LES of supersonic combustion [18, 19, 36], it is a simplification which has to be discussed. The thermal flame thickness of an unstrained stoichiometric ethylene/air flame at 0.66 bar without preheating the reactants, is around $0.4 \mathrm{~mm}$. A resolution of $100 \mu \mathrm{m}$, may be considered sufficient to describe the flame front, especially since in the present simulation it is thickened by turbulence and the mixing with burned gases. However, this resolution is still too coarse to describe accurately the 
source terms especially those of intermediate species. The subgrid Damköhler number, $D a_{s g s}(\mathrm{Krol}$ et al. [37], Duwig et al. [38]) can be introduced to quantify the reliability of the no-model assumption. $D a_{s g s}$ is defined as the ratio between a time characteristic of the smallest resolved structure $\tau_{s g s}$ and a chemical timescale $\tau_{c}$. For a turbulent flow, if $D a_{s g s}$ is much smaller than unity, the no-model assumption is supposed to be valid. Several expressions of the subgrid Damköhler number can be constructed [19] depending on the expressions retained for the chemical timescale and the resolved turbulence timescale. For the chemical timescale, Duwig et al. [38] uses a timescale associated to $1 \mathrm{D}$ laminar premixed flame : $\tau_{c}^{S_{L}}=\delta_{f} / S_{L}$, where $\delta_{f}$ is the laminar flame thickness and $S_{L}$ the laminar flame speed. This approximation gives satisfying results in a subsonic configuration. Cocks [39] defines the chemical timescale as the ratio between the density and the reaction rate of water for a hydrogen flame: $\tau_{c}^{\text {Cocks }}=\rho / \dot{\omega}_{H_{2} O}$. This expression is not very restrictive and, following Guven and Ribert [19], a chemical time scale for each species, $k$, based on the species mass fraction and reaction rate has been introduced in this work

$$
\tau_{c, k}=\frac{\rho Y_{k}}{\left|\dot{\omega}_{k}\right|}
$$

The characteristic chemical time scale is taken either as the minimum of $\tau_{c}^{k}$ estimated considering the 22 species of the chemical scheme (noted $\tau_{c}^{a l l}$ ) or only as the minimum taken from the three major species: $k=\mathrm{CO}, \mathrm{CO}_{2}$ or $\mathrm{H}_{2} \mathrm{O}$ (noted $\tau_{c}^{\text {red }}$ ). Both time scales, $\tau_{c}^{\text {all }}$ and $\tau_{c}^{\text {red }}$, are computed with the instantaneous values of temperature and species concentrations and vary spatially. Another option, which has not been tested in this work, would be to determine the chemical time scale with the Chemical Explosive Mode Analysis (CEMA) [40].

Also several expressions of the resolved turbulent timescale can be encountered using the smallest resolved turbulent structure, such as [41, 42]

$$
\tau_{s g s}^{\nu_{T}}=\frac{\left(C_{s} \Delta\right)^{2}}{v_{t}}
$$

where $C_{s}=0.15$ is the Smagorinsky constant, $\Delta=\left(\Delta_{x} \Delta_{y} \Delta_{z}\right)^{1 / 3}$ the cutoff length of the LES filter 
and $v_{t}$ the subgrid viscosity. Since, in the present simulations, the dynamic Smagorinsky closure has been employed, locations where $v_{t}$ is very small are present. The following expression of $\tau_{s g s}$ obtained from the relationship between the subgrid viscosity and the resolved deformation tensor $\left(\tilde{S}_{i j}\right)$, has then been used

$$
\tau_{s g s}=\frac{1}{\sqrt{2 \tilde{S}_{i j} \tilde{S}_{i j}}},
$$

Three different estimations of the subgrid Damköhler number have then be computed: $D a_{\text {sgs }}^{S_{L}}=$ $\tau_{c}^{S_{L}} / \tau_{s g s}, D a_{s g s}^{\text {all }}=\tau_{c}^{\text {all }} / \tau_{s g s}$ and $D a_{s g s}^{\text {red }}=\tau_{c}^{r e d} / \tau_{s g s}$

The analysis is carried out on instantaneous solutions. To avoid non-significant values, the subgrid Damköhler is only computed in cells featuring a heat release greater than $1 \%$ of the maximum heat release and the species chemical time scale of a cell is taken into account only if its source term verifies: $\left|\dot{\omega}_{k, \text { cell }}\right| \geqslant 0.01\left|\dot{\omega}_{k, \text { max }}\right| . D a_{s g s}^{\text {all }}, D a_{s g s}^{\text {red }}$ and $D a_{s g s}^{S_{L}}$ are compared in Fig. 14 . The percentage of cells where the sugrid Damköhler number verifies $D_{s g s} \in\left[D a_{i}, D a_{i}+\epsilon_{D a}\right]$ where $\epsilon_{D a}$ takes the value 0.05 is plotted for each expression of the subgrid Damköhler number.

The subgrid subgrid Damköhler number based on premixed flamelet chemical time scale always stays below 0.05 . When based on the three major species chemical time scale, the subgrid Damköhler stays very small with $95 \%$ of cells verifying $D a_{s g s} \leqslant 0.05$. When based on all the species contribution, the subgrid Damköhler takes higher values with only $65 \%$ of cells verifying $D a_{s g s} \leqslant 0.05$ but still $83 \%$ cells verifying $D a_{s g s} \leqslant 0.1$. As expected, minor species contributions are less likely to be accurately captured by LES with this no-model approach.

The Partially Stirred Reactor Model (PaSR), used with success by some authors in the context of supersonic combustion [43-45], introduces the subgrid Damköhler number as an ingredient where it is used to determine the fine structure volume fraction, usually using the chemical characteristic time based on premixed flamelet

$$
\gamma^{*}=\frac{1}{1+D a_{s g s}^{S_{L}}}
$$

In this model, if $\gamma^{*}$ is close to 1 (i.e. $D a_{s g s}^{S_{L}}$ small), then the subgrid contribution vanishes and 
the filtered source term is directly evaluated from the filtered quantities. With the expression (3), the subgrid Damköhler based on premixed flamelet properties is indeed below 0.05. Another estimation has been performed using the same expression for the subgrid turbulent time scale than than used by Moule et al. [43], which conducts to

$$
D a_{s g s}^{S_{L}} *=0.039 \frac{\Delta^{2} v^{1 / 4}}{v_{t}^{5 / 4}} \frac{S_{L}}{\tau_{L}}
$$

This estimation of $D a_{s g s}^{S_{L}} *$ is plotted in Fig. 15 for LES performed with the fine and the coarse meshes. For both resolutions, the subgrid Damköhler is always found below 0.02 with a slightly higher number of cells below 0.01 for the refined mesh, leading to $\gamma^{*} \sim 1$. Therefore, the PaSR model, if implemented, would provide in these simulations the same results than the quasi-laminar model which has been used.

Finally, one may consider that the use of a no-model approach is well grounded in this configuration with the chosen mesh resolutions.

\subsection{Preferential combustion conditions}

\subsubsection{Mach number}

The purpose of this section is to investigate the range of velocity where combustion is most likely to take place. A threshold on heat release rate identical to the condition of the section 5.1 is considered, with only cells featuring a heat release greater than $1 \%$ of the maximum heat release included in the statistics. The data used for the statistics have been obtained with the fine mesh.

Fig. 16 shows a cut in the centerplane between two injectors of heat release rate and Mach number. The isoline Mach = 1 (white line) separates the domain into two regions: subsonic below and supersonic above. Combustion occurs only inside the cavity and in the mixing layer. There is almost no combustion in supersonic flow and the highest heat release rate is found at the mixing layer, featuring Mach $=0.5$. Two quantities are defined to better quantify the observed phenomena. The first quantity indicates the number of cells at each Mach number and is defined as the ratio 
of number of cells involved in each interval of Mach number on the total number of cells, $C_{M a, i}$, defined as:

$$
C_{M a, i}=\frac{N_{c, M a, i}}{N_{T}}
$$

with $N_{c, M a, i}$ the number of cells verifying $M a \in\left[M a_{i}, M a_{i}+\epsilon_{M a}\right]$, where $\epsilon_{M a}=0.1$ is the interval range. The second quantity is based on the conditional mean of heat release rate on Mach number, $<\dot{\omega}_{E} \mid M a>$, to understand which Mach range features the highest heat release. The conditional mean is adimensionalized by the mean heat release $<\dot{\omega}_{E}>$ :

$$
R_{M a}=\frac{<\dot{\omega}_{E} \mid M a>}{<\dot{\omega}_{E}>}
$$

These two quantities allow for characterising the heat release typical of a Mach range along with the number of cells which are concerned. Fig. 17 shows these two quantities. This plot quantifies what was observed on snapshots in Fig. 16 stating that the highest chemical activity appears at Mach $=0.5$ and over $95 \%$ of combustion occurs at subsonic speeds. Combustion is still probable, however with a very low occurence, up to Mach 1.8. Cells where combustion is most likely to be found, feature Mach numbers between 0.1 and 0.3 representing approximately $40 \%$ of cells having $\dot{\omega}_{E, \text { cell }} \geq 0.01 \dot{\omega}_{E, \text { max }}$, but with lower intensity compared to the average heat release $\left(R_{M a}=0.9\right)$. This region corresponds to the outer part of the large recirculation zone. If one consider that compressibility effect over the chemical reactions can be neglected up to Mach $0.4,60 \%$ of the cells are concerned, which leaves $40 \%$ of the cells where compressibility effects impact on the chemical model might not be neglected for example if a tabulated flamelet approach were to be used [2].

\subsubsection{Flame regimes}

Flame regimes can be characterized by the flame index which was first introduced by Yamashita et al. [46] to distinguish premixed from nonpremixed combustion. This index is based on geometrical considerations depending on fuel $(F)$ and oxidizer $\left(\mathrm{O}_{2}\right)$ mass fraction gradients. 
If the gradients follow the same direction, the combustion regime is accounted as premixed, and opposite gradients signal nonpremixed flames. Domingo et al. [47] have introduced a normalized flame index expression to analyse the flame regime distribution:

$$
\text { F.I. }{ }^{\text {Norm }}=\frac{1}{2}\left(1+\frac{\nabla Y_{F} \cdot \nabla Y_{O_{2}}}{\left|\nabla Y_{F} \cdot \nabla Y_{O_{2}}\right|}\right)
$$

The premixed regime occurs when F.I. ${ }^{\text {Norm }}=1$ while F.I. ${ }^{\text {Norm }}=0$ signals nonpremixed flames. The flame index, later modified by Lock et al. [48] includes a weighting factor allowing to distinguish between lean and rich combustion:

$$
\text { F.I. }=\frac{1}{2} \frac{Z-Z_{s t}}{\left|Z-Z_{s t}\right|} \times\left(1+\frac{\nabla Y_{F} . \nabla Y_{O_{2}}}{\left|\nabla Y_{F} . \nabla Y_{O_{2}}\right|}\right)
$$

where $Z$ is the mixture fraction from Bilger et al. [35] and $Z_{s t}$ the stoichiometric mixture fraction. With this expression, which is the one used in this paper, F.I. $=1$ for the rich premixed regime and F.I. $=-1$ for the lean one, while F.I. $=0$ still signals nonpremixed regime. To avoid a division by zero when $Z=Z_{s t}$, the factor $\left(Z-Z_{s t}\right) /\left|Z-Z_{s t}\right|$ is set to one, if $Z=Z_{s t}$. This assumption leaves the flame index to take the values 0 for nonpremixed flames and 1 for stoichiometric premixed flames.

When using complex or semi-detailed kinetic schemes, the fuel, here ethylene, can decompose before reaching the reaction zone, leading to insignifiant fuel gradients which makes the flame index indeterminate. To overcome that difficulty, the fuel mass fraction will be built on all the hydrocarbons involved in reactions:

$$
Y_{F}=Y_{C_{2} H_{4}}+Y_{C_{2} H_{2}}+Y_{C_{3}}+Y_{C_{4}}+Y_{C_{2} H_{6}}+Y_{C_{3} H_{6}}
$$

Taking in consideration only cells with $\left|\dot{\omega}_{E}\right|>0.01 \dot{\omega}_{E \text {,max }}$, this formulation of $Y_{F}$ leads to less than $0.2 \%$ of points where $\nabla Y_{F} \cdot \nabla Y_{O_{2}}=0$ for the fine mesh. These few locations have been eliminated in the results presented in this paper.

The flame index is displayed in Fig. 18 computed solely in relevant zones where the heat release 
is greater than $1 \%$ of its maximum value. The inner cavity is mostly controlled by nonpremixed combustion while the premixed regime is predominant in the mixing layer and the cavity ramp. Using the distribution of the heat release rate from figure 10 , the reactive zones can be cast in four major combustion regimes: (I) a weak reacting zone in the mixing layer developing above the secondary recirculation zone, (II) a significant reacting zone at the interface between the two recirculating bubbles into the cavity, (III) a strong and efficient reacting zone in the mixing layer above the primary recirculating zone, (IV) a thin reacting zone in the vicinity of the ethylene injection. The flame index distribution helps us to determine the burning regime of these four zones. The zone (I) is fed by ethylene mixed with hot burnt products burning in a diffusive regime. The zone (II) burns mostly in a diffusive regime. The zone (III) burns a well mixed mixture. In this latter zone, the combustion is back supported by the presence of hot gases into the cavity. The zone (IV) burns the ethylene just at the exit of the injector in a pure diffusive regime. The combustion modes in the cavity appear then very complex and no privileged regime can be easily extracted.

Fig. 19 shows the conditional mean of heat release rate by flame index $<\dot{\omega}_{E} \mid$ F.I. $>$ adimensionalized by the overall mean heat release $<\dot{\omega}_{E}>$ (blue patterns) and the contribution of each flame regime as characterised by the flame index to the heat release, $C_{F I}$ (red histogram) defined as follow:

$$
R_{F I}=\frac{<\dot{\omega}_{E} \mid F . I .>}{<\dot{\omega}_{E}>} \quad \text { and } \quad C_{F I}=R_{F I} \frac{N_{F I}}{N_{T}} \text { with } N_{T}=\sum_{F I} N_{F I}
$$

where $N_{F I}$ is the number of points in the interval of considered flame index and $N_{T}$ the total number of points. The conditional mean heat release rate is similar for each flame index value: from $R_{F I}=0.8$ in the nonpremixed flames to $R_{F I}=1.1$ in the premixed flames regardless of the mixture. None of the regimes is only marked by either strong or weak combustion. The values taken by $C_{F I}$ indicate that most of the contributions to the overall heat release rate come from premixed flames, over $75 \%$, where the lean premixed regime contribution is approximately $60 \%$.

The contribution to the heat release rate conditioned by the flame index estimated in each 
plane $(y, z)$, along the $x$ axis, $C_{F I}(x)$, is displayed in Fig. 20. It shows that the front of the cavity $(x<0.265 \mathrm{~m})$ is mainly controlled by nonpremixed combustion where approximately $100 \%$ of heat release rate is due to nonpremixed flames. This region corresponds to auto ignition in a diffusive regime of the fresh air arriving from the nozzle with the mixture of ethylene and hot burned product present in the small anti-clockwise recirculation. In the middle of the cavity $(0.265<x<0.29)$, premixed flames start to take place and any combustion regime can be encountered. At the rear of the cavity, the lean premixed regime predominates with over $75 \%$ of contribution to heat release rate at almost any position from $x=0.29 \mathrm{~m}$. The remaining $25 \%$ is principally from nonpremixed flames, almost no rich premixed flames can be observed from the cavity ramp.

\subsection{Residence time}

The notion of residence time, $\tau_{r}$, is particularly important in the context of cavity combustion. It makes it possible to evaluate whether the mixing time of the reagents is well-ensured in order to have as complete a combustion as possible, and thus to ensure a stable flame. $\tau_{r}$ can be estimated empirically by following the work of Davis and Bowersox [33, 49]: $\tau_{r}=40 D / U_{\infty}$, where $D$ is the cavity depth and $U_{\infty}$ the velocity above the cavity. It leads to $\tau_{r}=0.9 \mathrm{~ms}$ in the current scramjet configuration. But, the residence time can be also computed directly in the simulation by adding a transport equation for $\tau_{r}[50]$ :

$$
\frac{\partial \bar{\rho} \widetilde{\tau}_{r}}{\partial t}+\frac{\partial}{\partial x_{i}}\left(\widetilde{\rho} \widetilde{u}_{i} \widetilde{\tau}_{r}\right)=\frac{\partial}{\partial x_{i}}\left[\bar{\rho}\left(v+v_{t}\right) \frac{\partial \widetilde{\tau}_{r}}{\partial x_{i}}\right]+\bar{\rho} S_{\widetilde{Z}}
$$

where $\bar{\rho}, \tilde{u}_{i}, x_{i}, t, v, v_{t}$ are respectively the resolved density, the resolved velocity, the space coordinate, the time, the laminar and subgrid eddy viscosities.

Enjalbert et al. [50] introduced a factor $S_{\widetilde{Z}}$, which is dependent of the mixture fraction $\widetilde{Z}$, to modulate the source term. The factor $S_{\widetilde{Z}}$ is equal to 1 in regions where fuel and oxidizer are mixed $\left(\widetilde{Z} \in[\epsilon, 1-\epsilon]\right.$ with $\left.\epsilon=10^{-4}\right)$ and 0 elsewhere. With this implementation, the residence time grows 
only in regions where mixing between fuel and oxidizer is acting. The residence time of the case with one injector, adiabatic walls and coarse mesh is displayed in Fig. 21 for averaged fields. The isoline $\tau_{r}=1 \mathrm{~ms}$ is displayed in white. Statistics are cumulated over $3 \mathrm{~ms}$. The large recirculation area is featuring low residence times, from $0.8 \mathrm{~ms}$ to $1.2 \mathrm{~ms}$, while the residence time in the small recirculation area is higher because of the lower local speed. Besides, the cavity residence time in the theory is determined by the mass exchange in the mixing layer, this time should correspond to the residence time of the lower part of the mixing layer which is around $0.8-0.9 \mathrm{~ms}$ in this work. This value of residence time is consistent with the empirical law from Davis and Bowersox [33, 49], but also with the literature where this time is found to be approximately $1 \mathrm{~ms}$ in every work about scramjets. Nevertheless, this more accurate evaluation of the residence time shows a significant variability depending on the location inside the cavity.

The scatter plot of residence time versus mixture fraction is displayed in Fig. 22. The highest residence time is found at $Z=0.3$ which is the mixture fraction found in the small recirculation area. As expected, a residence time close to 0 is found in regions with quasi-pure oxidizer $(Z \approx 0)$ or quasi-pure fuel $(Z \approx 1)$. A stoichiometric mixture $\left(Z_{s t}=0.06366\right)$ requires only $0.3 \mathrm{~ms}$ to be obtained, and past $\tau_{r}=0.8 \mathrm{~ms}$, no stoichiometric mixture can be found. It leads to the conclusion that the stoichiometric conditions are obtained very rapidly and does not last long in the cavity $(<0.5 \mathrm{~ms})$ due to intense mixing. The flammable region corresponds to a mixture comprise between $\phi=0.4$ and $\phi=5$ (red lines in Fig. 22). The lower flammability limit is featuring low residence times $\left(\tau_{r}=0.15-0.45 \mathrm{~ms}\right)$ while the upper flammability limit can only be reached when the residence time is higher than $0.6 \mathrm{~ms}$, up to $2.9 \mathrm{~ms}$. The mixing time of a mixture with equivalence ratio $\phi=5$ is therefore reached around $0.6 \mathrm{~ms}$ in this cavity.

The dimensionless conditional mean of the heat release on residence time $R_{\tau}$, and percentage of cells contributing to the statistics in each interval $i$ of residence time $C_{\tau, i}$ have been computed in cells with heat release rate higher than $1 \%$ of maximum heat release rate, to investigate the interaction between combustion and residence time. The expressions of $R_{\tau}$ and $C_{\tau, i}$ are similar to 
$R_{M a}$ and $C_{M a, i}$

$$
R_{\tau}=\frac{<\dot{\omega}_{E} \mid \tau_{r}>}{<\dot{\omega}_{E}>} \text { and } C_{\tau, i}=\frac{N_{c, \tau, i}}{N_{T}}
$$

where $<\dot{\omega}_{E} \mid \tau_{r}>$ is the conditional mean of heat release rate on the residence time and $<\dot{\omega}_{E}>$ the mean heat release rate over the entire domain. $N_{c, \tau, i}$ is the number of cells verifying $\tau_{r} \in$ $\left[\tau_{r_{i}}, \tau_{r_{i}}+\epsilon_{\tau}\right]$, with $\epsilon_{\tau}=0.1 \mathrm{~ms} . N_{T}$ is the total number of cells. $R_{\tau}$ and $C_{\tau, i}$ are displayed in Fig. 23 . Significant combustion $\left(C_{\tau, i}>0.01\right)$ occurs in a wide range of residence time from 0.2 to $1.3 \mathrm{~ms}$. Almost no combustion can be found in regions where $\tau_{r}$ exceeds 1.5 ms. Looking back at Fig. 21. these regions correspond actually to the small recirculation zone. The dimensionless conditional mean of the heat release on residence time $R_{\tau}$ indicates that the region with the highest chemical activity is featuring residence time of 0.4-0.6 ms. Such strong combustion can be found at the exit of the injector or in the mixing layer above the large recirculation area. Over a residence time of $0.6 \mathrm{~ms}$, the chemical activity starts decreasing while the number of cells contributing to heat release stays relatively the same until $\tau_{r}=1.1 \mathrm{~ms}$. The region with residence time between 0.6 and 1 or $1.1 \mathrm{~ms}$ corresponds actually to the large recirculation area where both strong and weak combustions coexist.

\section{Conclusion}

Large-eddy simulations of combustion in a cavity-based scramjet have been performed with success with a reduced but accurate kinetics and the hypothesis that eventual subgrid fluctuation of temperature and species can be neglected in the determination of the filtered source terms. The numerical results for the reactive and non-reactive cases are in fair agreement with the experimental measurements available for the AFRL test-bench [6]. With a resolution of 100 to $200 \mu \mathrm{m}$ in the flame region, the use of the direct evaluation of the source terms from the transported quantities

has been justified based on the computation of subgrid Damköhler numbers. The combustion is found to take place in region where the flow is largely subsonic and preferentially in the mixing layer over the cavity. Also, the residence time in the cavity has been tracked, showing that the usual 
approximation of an averaged residence time around $1 \mathrm{~ms}$ is reasonable even if a strong dispersion is observed from $3 \mathrm{~ms}$ in the secondary recirculation down to $0.1 \mathrm{~ms}$ in the mixing layer. The combustion is preferentially found within a range of the residence time between 0.2 to $1.3 \mathrm{~ms}$. A great diversity of combustion regimes determined by the flame index was evidenced suggesting that reliable modeling of the filtered source terms might prove tricky if coarse meshes were to be employed or if the transported chemistry were to be replaced by tabulated chemistry.

\section{Acknowledgments}

The present work has been supported by the French Department of Defence (DGA). Computations ressources were provided by CRIANN and Genci (allocation 2018-020152).

\section{References}

[1] E. D. Gonzalez-Juez, A. R. Kernstein, R. Ranjan, S. Menon, Advances and challenges in modeling high-speed turbulent combustion in propulsion systems, Progress in Energy and Combustion (60) (2017) 26-67.

[2] A. Saghafian, L. Shunn, D. A. Philips, F. Ham, Large Eddy Simulations of the HiFiRE Scramjet Using a Compressible Flamelet/Progress Variable Approach, Proc. Combust. Inst. 35 (2015) 2163-2172.

[3] G. Lacaze, Z. Vane, J. Oefelein, Large Eddy Simulation of the HIFiRE Direct Connect Rig Scramjet Combustor, AIAA Paper (2017-0142).

[4] X. Wang, F. Zhong, H. Gu, X. Zhang, Numerical Study of Combustion and Convective Heat Transfer of a Mach 2.5 Supersonic Combustor, Applied Thermal Engineering 89 (2015) 883896.

[5] E. Hassan, D. Peterson, D. Walters, E. Luke, Dynamic hybrid Reynolds-Averaged NavierStokes/Large-Eddy Simulation of a supersonic cavity: Chemistry effects, J. Propul. Power 35 (1) (2019) 1-12. 
[6] S. G. Tuttle, C. D. Carter, K.-Y. Hsu, Particle Image Velocimetry in a nonreacting and reacting High-Speed Cavity, J. Propul. Power 30 (13) (2014) 576-591.

[7] S. Nakaya, Y. Hikichi, Y. Nakazawa, K. Sakaki, M. Choi, M. Tsue, M. Kono, S. Tomioka, Ignition and Supersonic Combustion Behavior of Liquid Ethanol in a Scramjet Model Combustor with Cavity Flame Holder, Proc. Combust. Inst. 35 (2015) 2091-2099.

[8] H. Wang, Z. Wang, M. Sun, Experimental Study of Oscillations in a Scramjet Combustor with Cavity Flameholders, Exp. Thermal and Fluid Sci. 45 (2013) 259-263.

[9] D. Micka, J. Driscoll, Combustion characteristics of a dual-mode scramjet combustor with cavity flameholder, Proc. Combust. Inst. 32 (2) (2009) 2397-2404.

[10] K. Jackson, M. Gruber, S. Buccellato, An Overview of the HIFiRE Flight 2 Project, in: 51st AIAA Aerospace Sciences Meeting, 2013.

[11] M. R. Gruber, A. S. Nejad, New Supersonic Combustion Research Facility, J. Propul. Power 11 (5) (1995) 1080-1083.

[12] H. Do, C. D. Carter, Q. Liu, T. Ombrellow, S. Hammack, T. Lee, K.-Y. Hsu, Simultaneous Gas Density and Fuel Concentration Measurements in a Supersonic Combustor Using Laser Induced Breakdown, Proc. Combust. Inst. 35 (2) (2015) 2155-2162.

[13] B. Duboc, G. Ribert, P. Domingo, Hybrid transported-tabulated chemistry for partially premixed combustion, Comput. Fluids 179 (2019) 206-227.

[14] B. Duboc, G. Ribert, P. Domingo, Evaluation of chemistry models on methane/air edge flame simulation, Proc. Combust. Inst. 37 (2) (2019) 1691-1698.

[15] G. Ribert, P. Domingo, L. Vervisch, Analysis of sub-grid scale modeling of the ideal-gas equation of state in hydrogen-oxygen premixed flames, Proc. Combust. Inst. 37 (2) (2019) 2345-2351.

[16] K. Bioche, G. Ribert, L. Vervisch, Simulating upstream flame propagation in a narrow channel after wall preheating: Flame analysis and chemistry reduction strategy, Combust. Flame 200 (2019) 219-231.

[17] U. Guven, G. Ribert, Impact of non-ideal transport modeling on supercritical flow simulation, 
Proc. Combust. Inst. 37 (3) (2019) 3255-3262.

[18] L. Bouheraoua, P. Domingo, G. Ribert, Large-eddy simulation of a supersonic lifted jet flame: Analysis of the turbulent flame base, Combust. Flame 179 (2017) 199-218.

[19] U. Guven, G. Ribert, Large-eddy simulation of supersonic hydrogen/oxygen combustion: application to rocketlike igniter, J. Propul. Power 34 (2) (2018) 291-307.

[20] C. Merlin, P. Domingo, L. Vervisch, Immersed boundaries in Large Eddy Simulation of compressible flows, Flow Turbul. Combust. 90 (1) (2013) 29-98.

[21] R. Swanson, R. Radespiel, E. Turkel, On some numerical dissipation schemes, J. Comput. Phys. 147 (1998) 518-544.

[22] M. Germano, U. Piomelli, P. Moin, W. H. Cabot, A dynamic subgrid-scale eddy viscosity model, Phys. Fluids 3 (7) (1991) 1760-1765.

[23] R. B. Bird, W. E. Stewart, E. N. Lightfoot, Combustion Physics, John Wiley and Sons, New York, 1960.

[24] J. Hirschfelder, C. Curtiss, R. Bird, Molecular theory of gases and liquids, John Wiley \& Sons, 1969.

[25] T. P. Coffee, M. Heimerl, Transport Algorithms for Premixed, Laminar Steady-State Flames., Combust. Flame 43 (1981) 273-289.

[26] C. R. Wilke, A viscosity equation for gas mixtures., J. Chem. Physics 18 (1950) 517-519.

[27] S. Mathur, P. K. Tondon, S. C. Saxena, Thermal conductivity of binary, ternary and quaternary mixtures of rare gases., Molecular Physics 12 (1967) 569-579.

[28] R. A. Baurle, Hybrid Reynolds-Averaged / Large Eddy Simulation of a Scramjet Cavity Flameholder, AIAA J. 55 (2) (2017) 544-560.

[29] J. L. Ruan, Large Eddy Simulation of Supersonic Combustion in Cavity-based Scramjets, Ph.D. thesis, INSA Rouen, 2019.

[30] W. Cabot, Large-eddy simulations with wall models, in: Center for Turbulence Research, Annual Research Briefs, 1995.

[31] M. R. Gruber, R. A. Baurle, T. Mathur, K.-Y. Hsu, Fundamental Studies of Cavity-Based 
Flameholder Concepts for Supersonic Combustors, J. Propul. Power 17 (1) (2001) 146-153.

[32] A. Ben-Yakar, R. K. Hanson, Cavity Flame-Holders for Ignition and Flame Stabilization in Scramjets: An Overview, J. Propul. Power 17 (4) (2001) 869-877.

[33] D. L. Davis, R. D. Bowersox, Stirred Reactor Analysis of Cavity Flameholders for Scramjets, AIAA Paper (97-3274).

[34] Z. Luo, C. S. Yoo, E. S. Richardson, J. H. Chen, C. K. Law, T. F. Lu, Chemical explosive mode analysis for a turbulent lifted ethylene jet flame in highly-heated coflow, Combust. Flame 159 (1) (2012) 265-274.

[35] R. W. Bilger, S. H. Starner, On reduced mechanisms for methane-air combustion in nonpremixed flames, Combust. Flame 80 (1990) 135-149.

[36] P. Boivin, A. Dauptain, C. Jimenez, B. Cuenot, Simulation of a supersonic hydrogen-air autoignition-stabilized flame using reduced chemistry, Combust. Flame 159 (2012) 1779_ 1790.

[37] M. C. Krol, M. J. Molemaker, J. V. G. de Arellano, Effets of turbulence and heterogeneous emissions on photochemically active species in the convective boundary layer, J. Geophys. Res. 105 (D5) (2000) 6871-6884.

[38] C. Duwig, K.-J. Nogenmyr, C.-K. Chan, M. J. Dunn, Large eddy simulations of a piloted lean premix jet flame using finite-rate chemistry, Combust. Theory Model. 15 (4) (2011) 537-568.

[39] P. Cocks, Large eddy simulation of supersonic combustion with application to scramjet engines, Ph.D. thesis, University of Cambridge, 2011.

[40] T. F. Li, C. S. Yoo, J. H. Chen, C. K. Law, Three-dimensional direct numerical simulation of a turbulent lifted hydrogen jet flame in heated coflow: a chemical explosive mode analysis., J. Fluid Mechanics 652 (2010) 45-64.

[41] J. F. Vinuesa, F. Porte-Agel, S. Basu, R. Stoll, Subgrid-scale modeling of reacting scalar fluxes in large-eddy simulations of atmostpheric boundary layers, Environ. Fluid Mech. 6 (2) (2006) 115-131.

[42] A. Yoshizawa, Statistical theory for compressible turbulent shear flows, with the application 
to subgrid modeling, Phys. Fluids 29 (2152).

[43] Y. Moule, V. Sabel'Nikov, A. Mura, Highly resolved numerical simulation of combustion in supersonic hydrogen-air coflowing jets, Combust. Flame 161 (2014) 2647-2668.

[44] V. Sabel'Nikov, C. Fureby, LES combustion modeling for high Re flames using a multi-phase analogy, Combust. Flame 160 (2013) 83-96.

[45] C. Fureby, Large eddy simulation modelling of combustion for propulsion applications, Phil. Trans. R. Soc. A 367 (2009) 2957-2969.

[46] H. Yamashita, M. Shimada, T. Takeno, A numerical study on flame stability at the transition point of jet diffusion flames, in: Symposium on Combustion, vol. 26, 27-34, 1996.

[47] P. Domingo, L. Vervisch, K. Bray, Partially premixed flamelets in LES of nonpremixed turbulent combustion, Combust. Theory Model. 6 (4) (2002) 529-551.

[48] A. J. Lock, A. M. Briones, X. Qin, S. K. Aggarwal, I. K. Puri, U. Hegde, Liftoff characteristics of partially premixed flames under normal and microgravity conditions, Combust. Flame 143 (2005) 159-173.

[49] D. L. Davis, R. D. W. Bowersox, Computational Fluid Dynamics Analysis of Cavity Flameholders for Scramjets, AIAA Paper (97-3270).

[50] N. Enjalbert, P. Domingo, L. Vervisch, Mixing time-history effects in Large Eddy Simulation of non-premixed turbulent flames: Flow-Controlled Chemistry Tabulation, Combust. Flame 159 (2012) 336-352. 


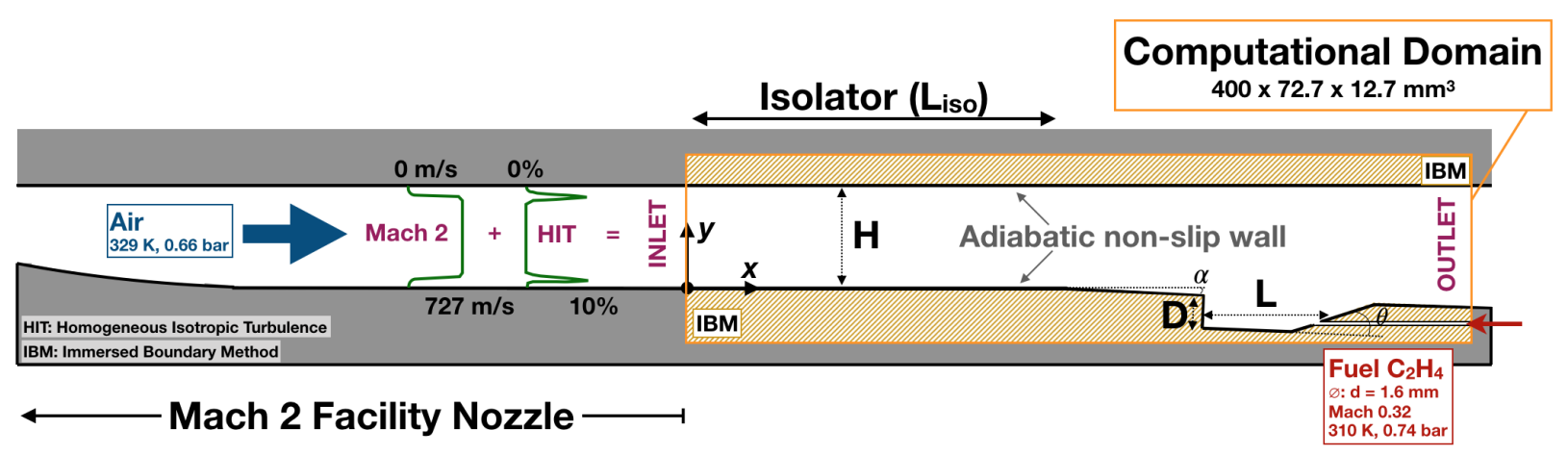

Figure 1: Sketch of the computational domain (center plane). the region coloured in grey or light brown corresponds to solid parts. $L_{\text {iso }}=177.8 \mathrm{~mm}, L=66 \mathrm{~mm}, D=16.5 \mathrm{~mm}, H=50.8 \mathrm{~mm}, \alpha=2.5^{0}, \theta=22.5^{0}$. For one injector, the domain width is $12.7 \mathrm{~mm}$ and $25.4 \mathrm{~mm}$ for two injectors.

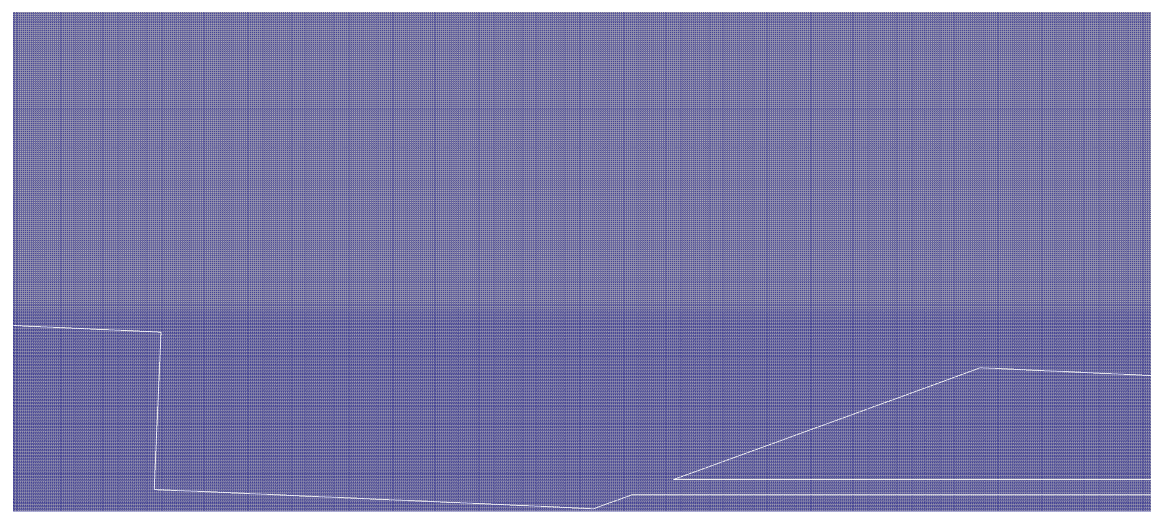

Figure 2: Zoom of the coarse mesh in a plane cutting one injector. The geometry boundary is plotted in white. 


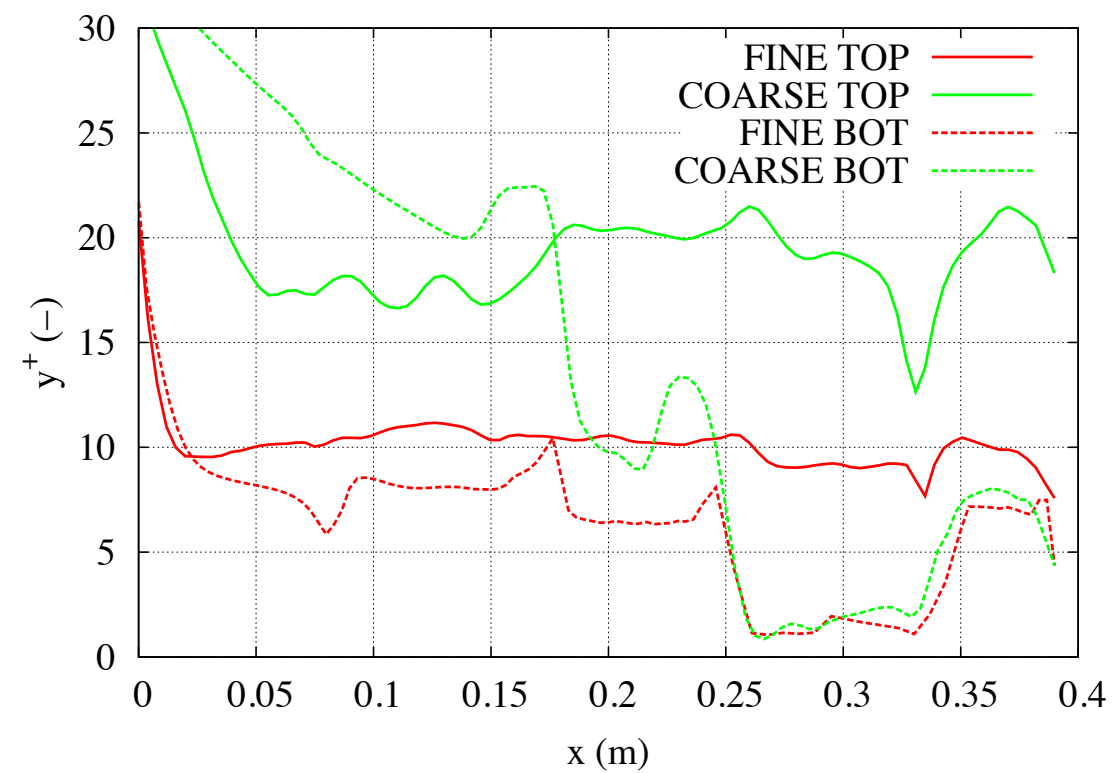

Figure 3: Dimensionless wall distance $y^{+}$for coarse and fine meshes at the upper wall (top) and bottom wall (bot).

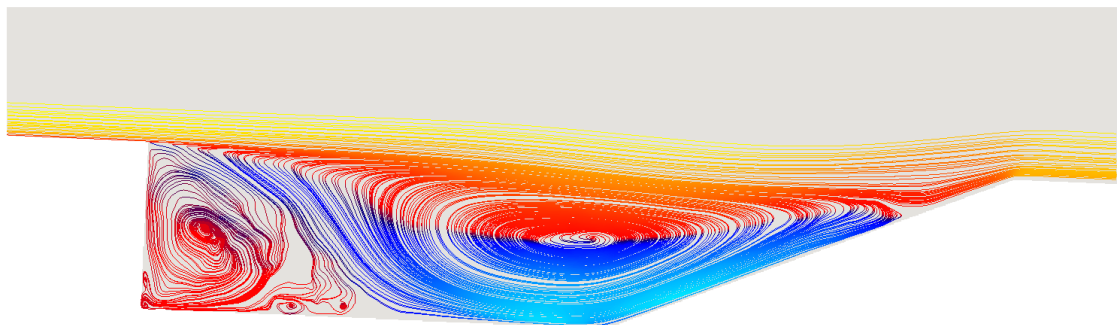

Averaged Velocity $X(\mathrm{~m} / \mathrm{s})$

$-250 \quad 0 \quad 400,600$

Figure 4: Non-reacting flow: Averaged streamlines, colored by averaged axial velocity. 

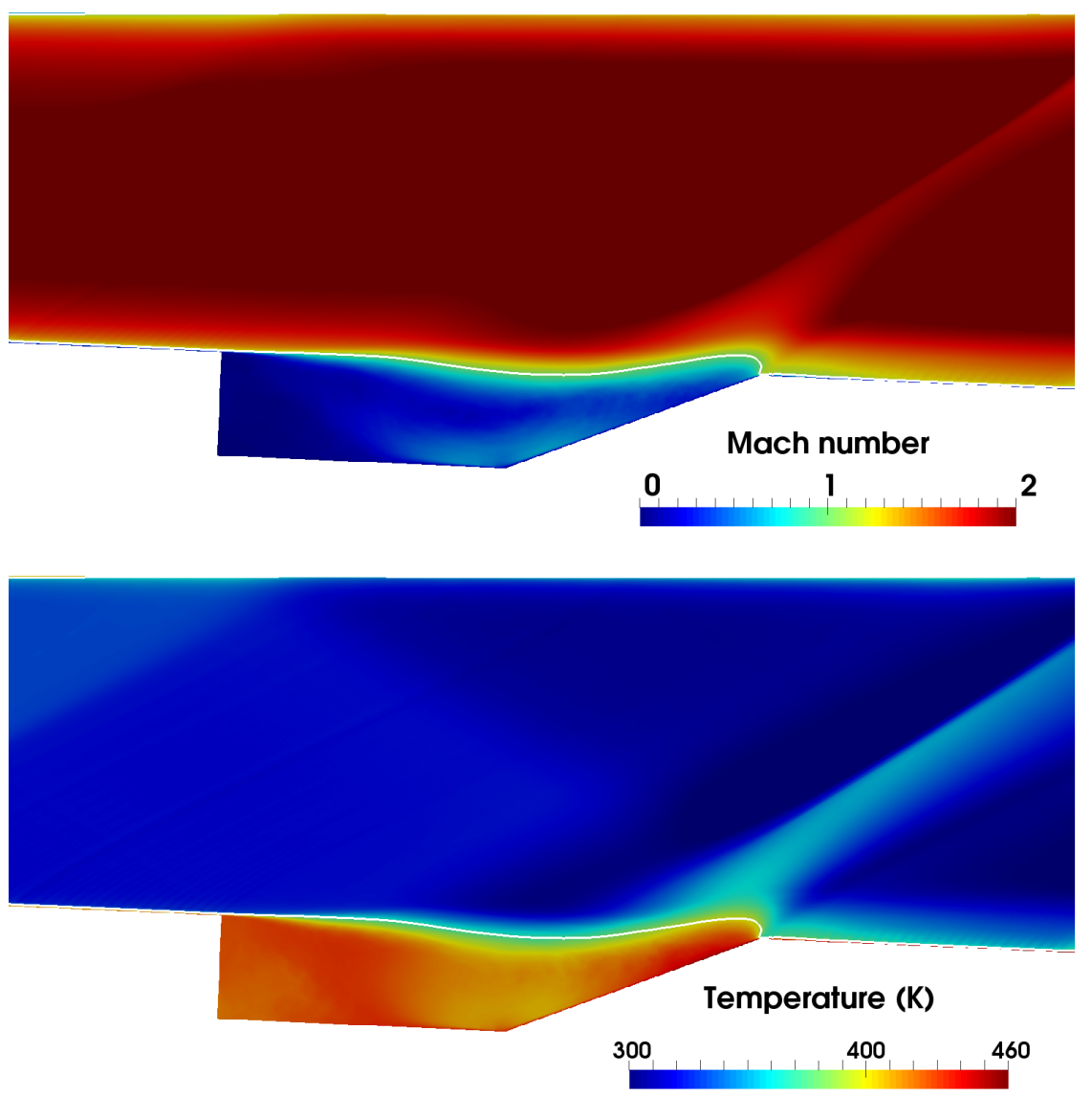

Figure 5: Averaged Mach number (top) and temperature (bottom). The isoline Mach = 1 is displayed with a white line. Fine mesh.

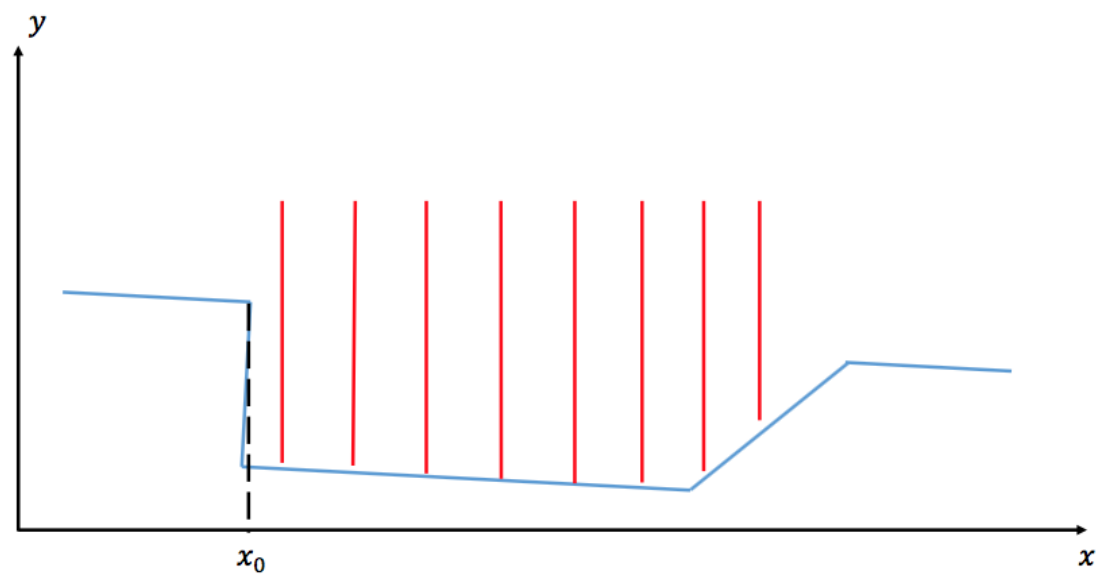

Figure 6: Positions where statistics are extracted: 2, 11, 20, 30, 39, 48, 57 and $66 \mathrm{~mm}$ respectively from the cavity front corner. $x_{0}=0.254 \mathrm{~m}$. 

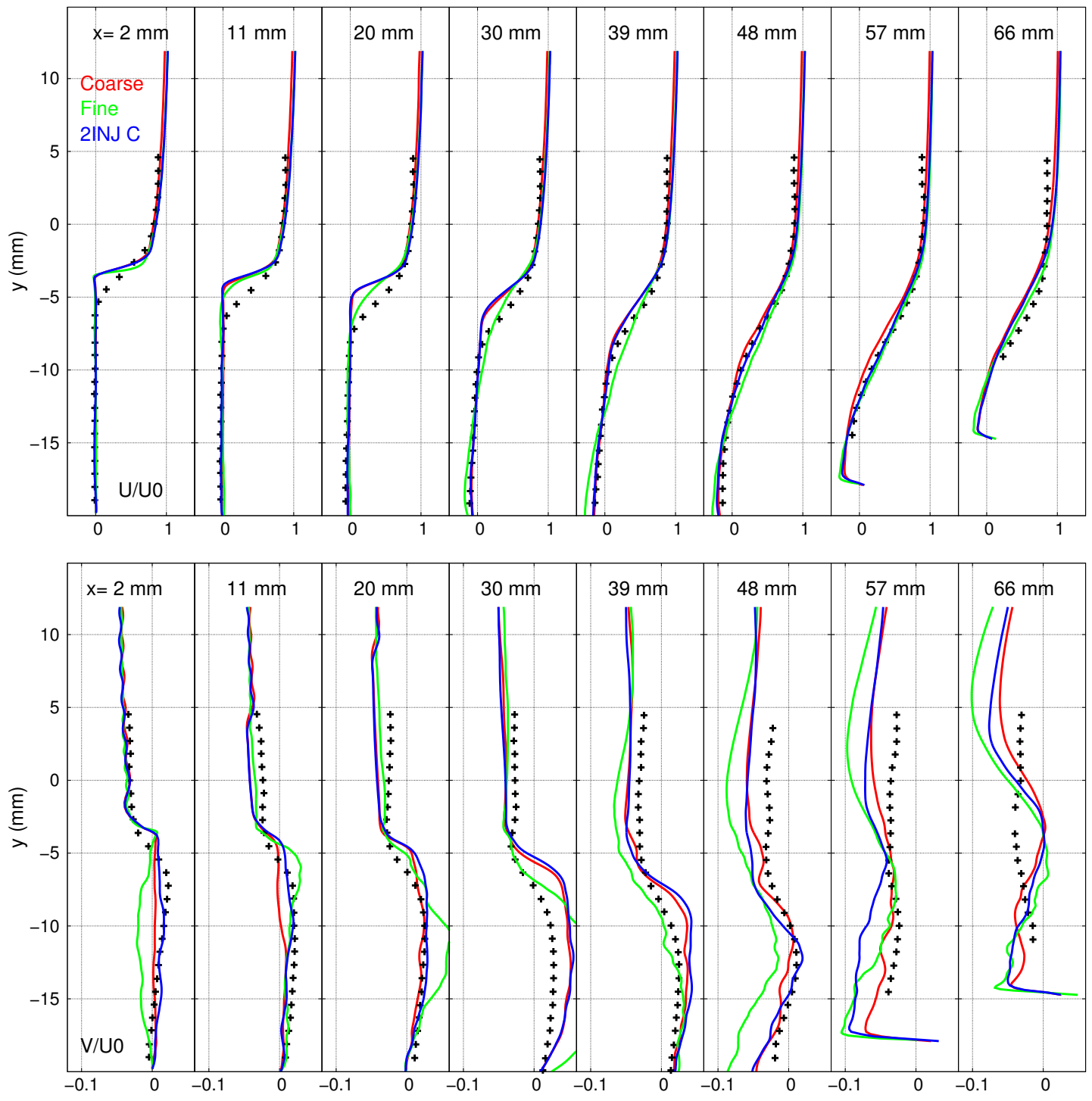

Figure 7: Comparison of the coarse (red and blue lines) and fine (green line) mesh computations with the experimental data [6]: (a) averaged streamwise velocity and (b) averaged transverse velocity. Red and green lines : one injector, blue line: two injectors. 


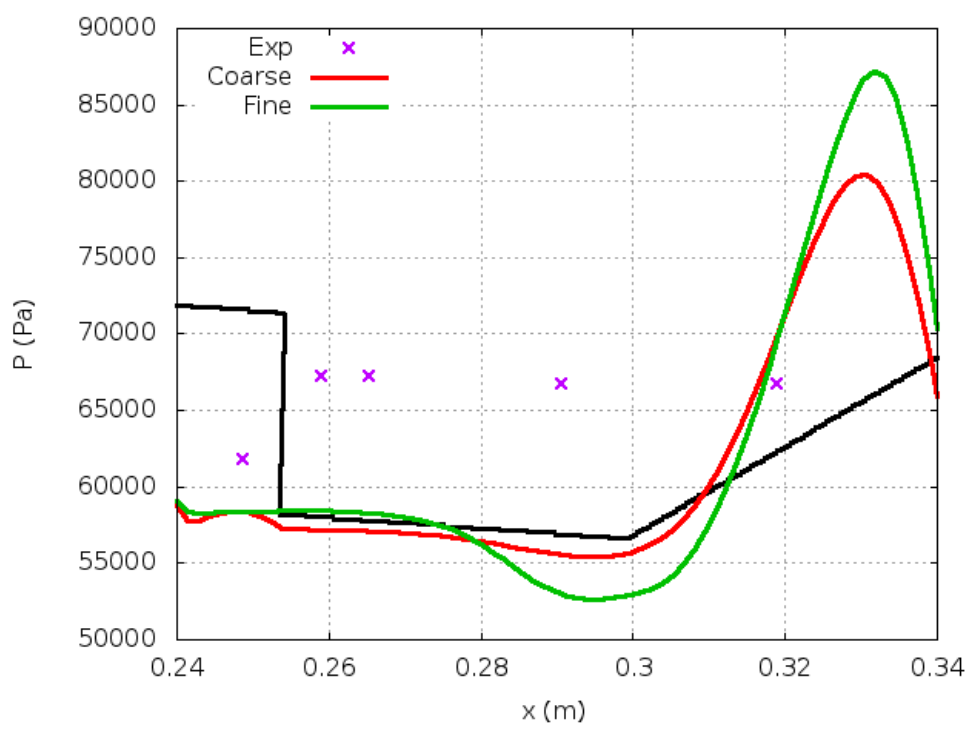

Figure 8: Averaged wall pressure field: comparison between coarse and fine meshes.

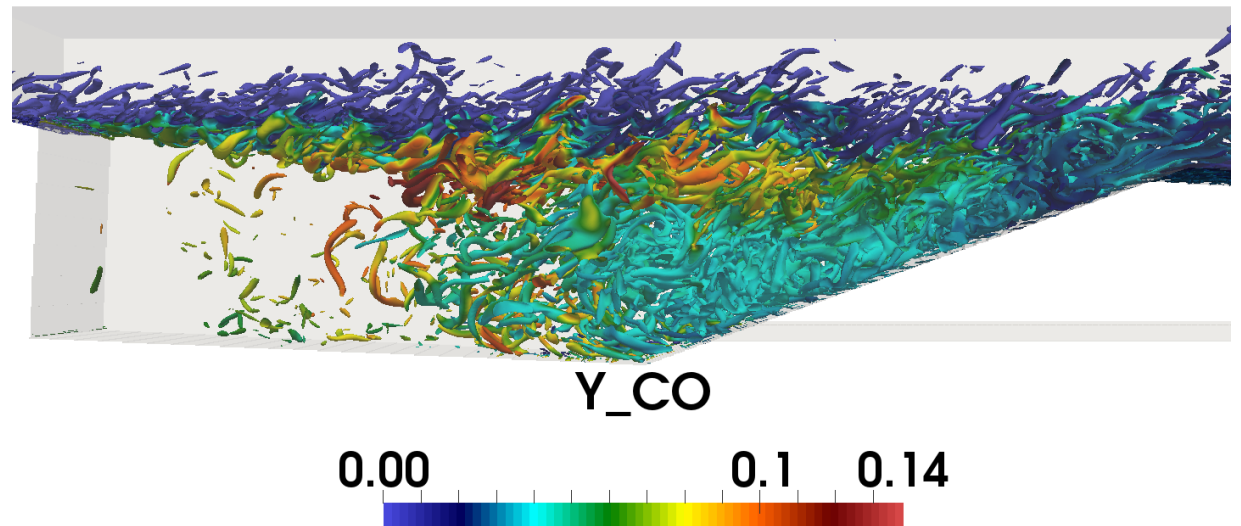

Figure 9: $Q$-criterion colored by $Y_{\mathrm{CO}}$ concentration with the fine mesh. 


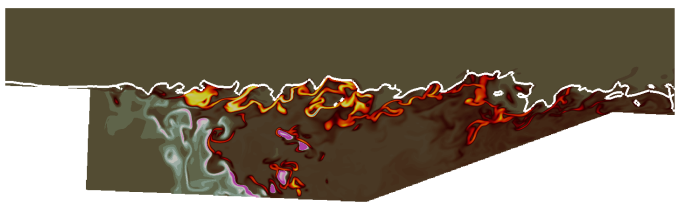

Heat Release (W/m3)
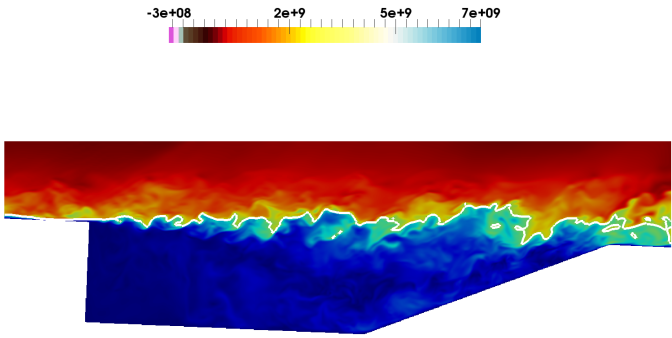

Mach number (-)

0 1

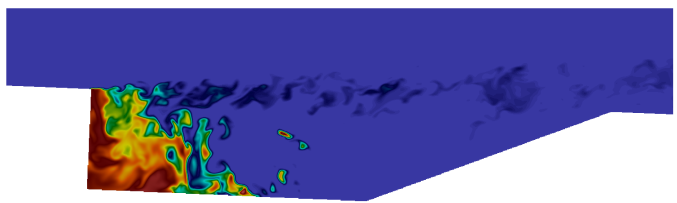

$\mathrm{Y}_{-} \mathrm{C} 2 \mathrm{H} 4(-)$

0.0

0.1 0.2

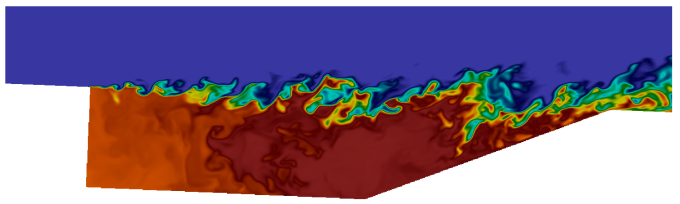

Y_CO2 (-)

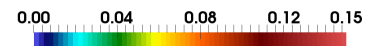

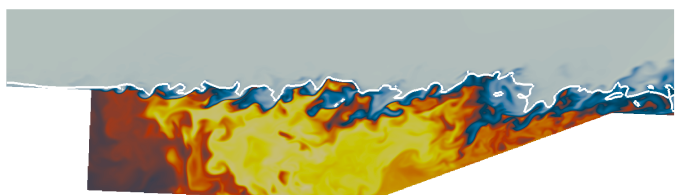

Temperature (K)

300

1000 $2000 \quad 2500$


Y_O2 (-)


Y_CO (-)

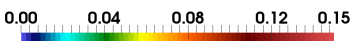

Figure 10: Instantaneous fields of heat release rate, temperature and mixture fraction, and mass fractions of $\mathrm{C}_{2} \mathrm{H}_{4}, \mathrm{O}_{2}$, $\mathrm{CO}$ and $\mathrm{CO}_{2}$ (fine mesh). The isoline Mach = 1 is displayed with a white line. 


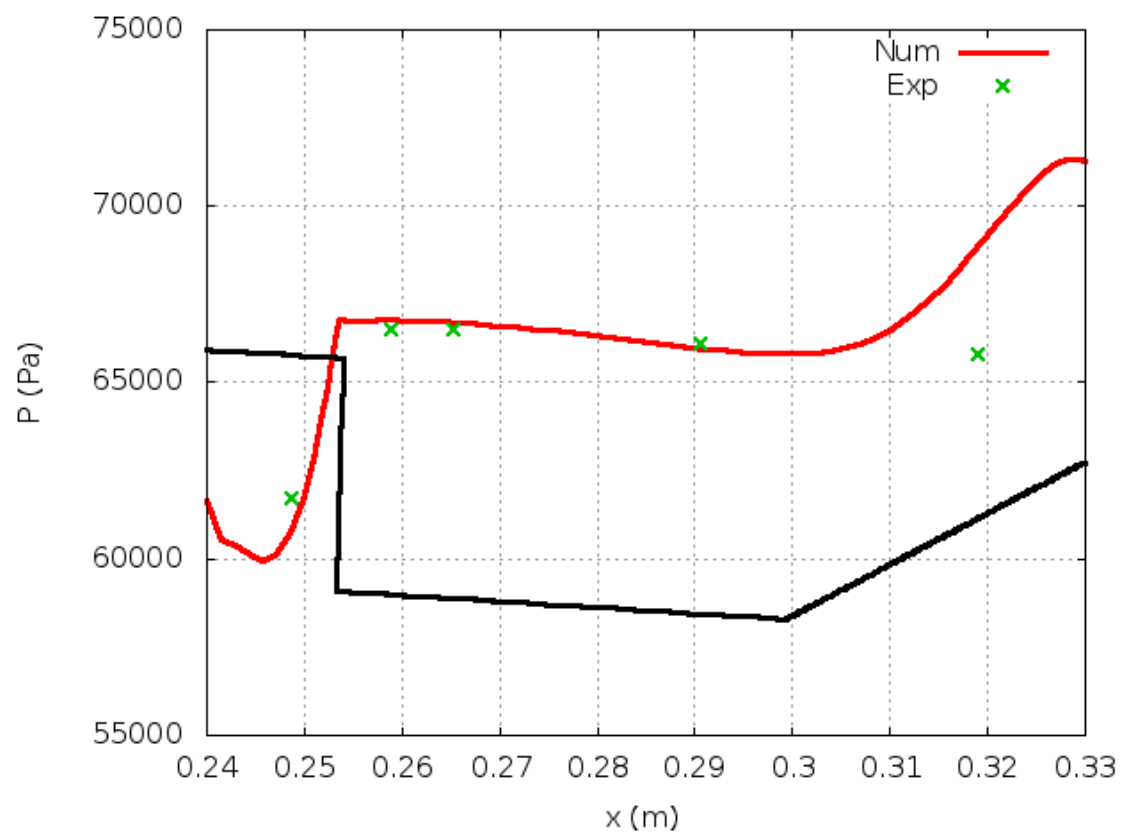

Figure 11: Reacting flow: Wall pressure inside the cavity with the fine mesh. Experiment (symbols), simulation (red line). 

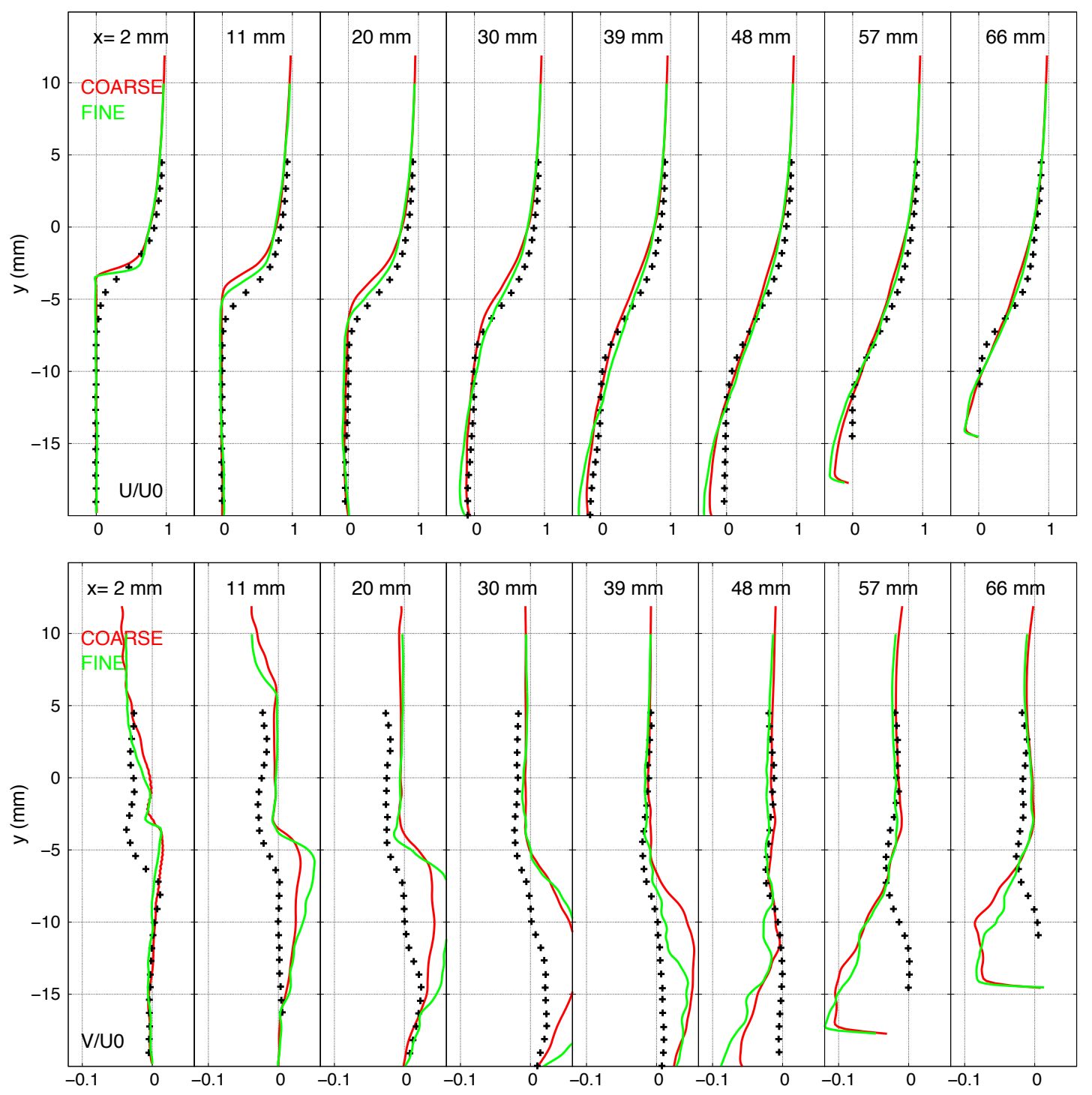

Figure 12: Averaged streamwise (top) and spanwise (bottom) velocity profiles inside the cavity: comparison between the numerical and the experimental data for coarse and fine mesh at the centerplane between two injectors. Refined and coarse meshes. 


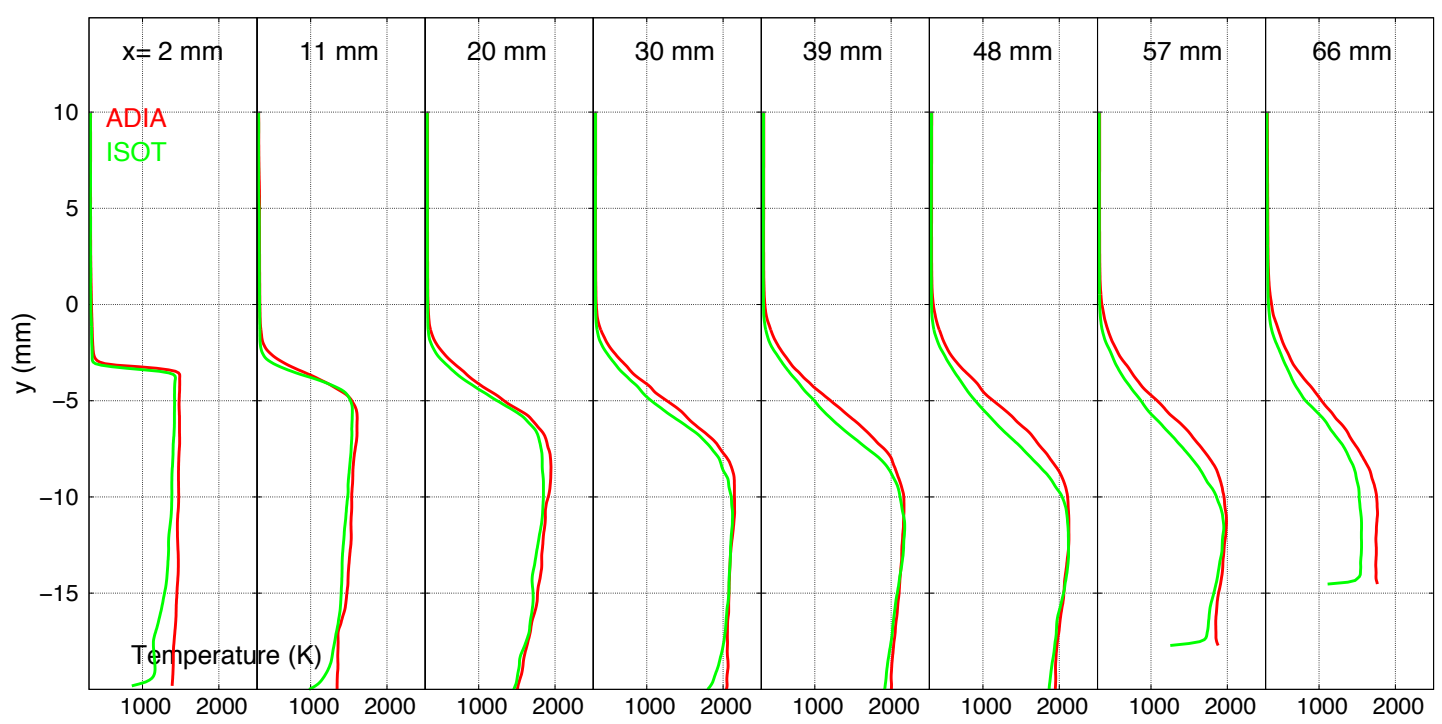

(a)

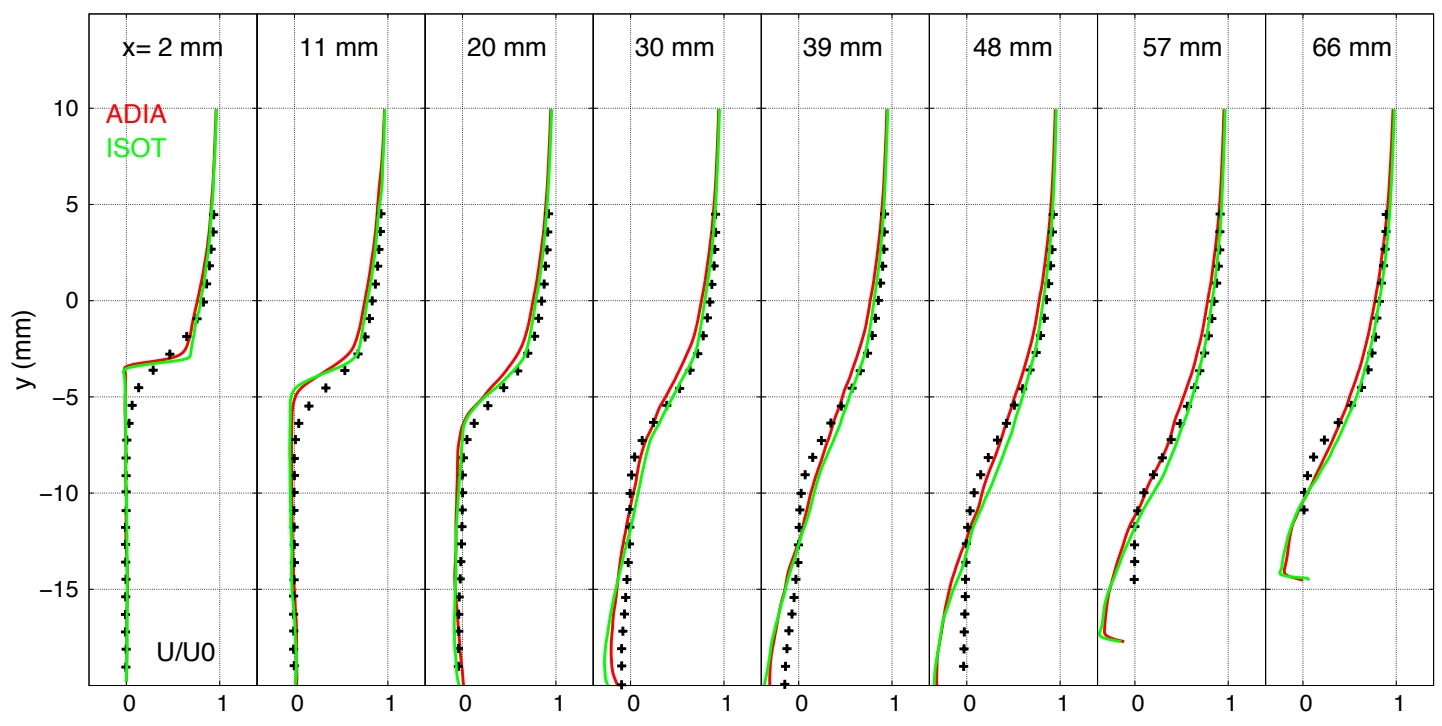

(b)

Figure 13: Top: temperature profile. Bottom: velocity profiles. Line: adiabatic wall, dashed lined: mixed fixed wall temperature/adiabatic wall. Dot: experiment.Velocity profiles inside the cavity. Refined Mesh, plane between two injectors. 


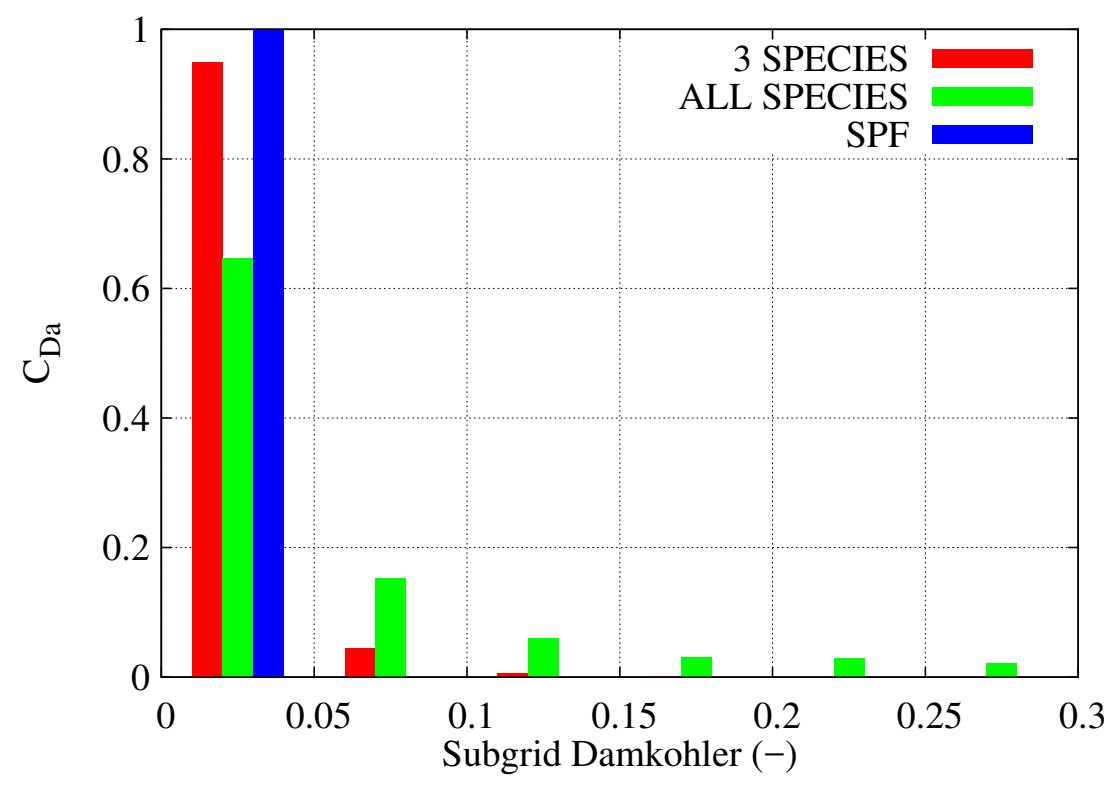

Figure 14: Cell ratio in each interval of subgrid Damköhler number. Red: $D a_{s g s}^{\text {red }}$ only the three major combustion products $\left(\mathrm{CO}, \mathrm{CO}_{2}, \mathrm{H}_{2} \mathrm{O}\right)$ chemical time scales are included. Green: $D a_{s g s}^{\text {all }}$ the 22 species chemical time scales are included. Blue: $D a_{s g s}^{S_{L}}$, chemical time scale based on stoichiometric premixed flamelet (SPF). Fine mesh.



Figure 15: Cell ratio in each interval of subgrid Damköhler number: $D a_{s g}^{S_{L}} *$. Red: fine mesh. Green: coarse mesh. 




Absolute value of Heat Release Rate ( $\mathrm{GW} / \mathrm{m} 3$ )

0

2
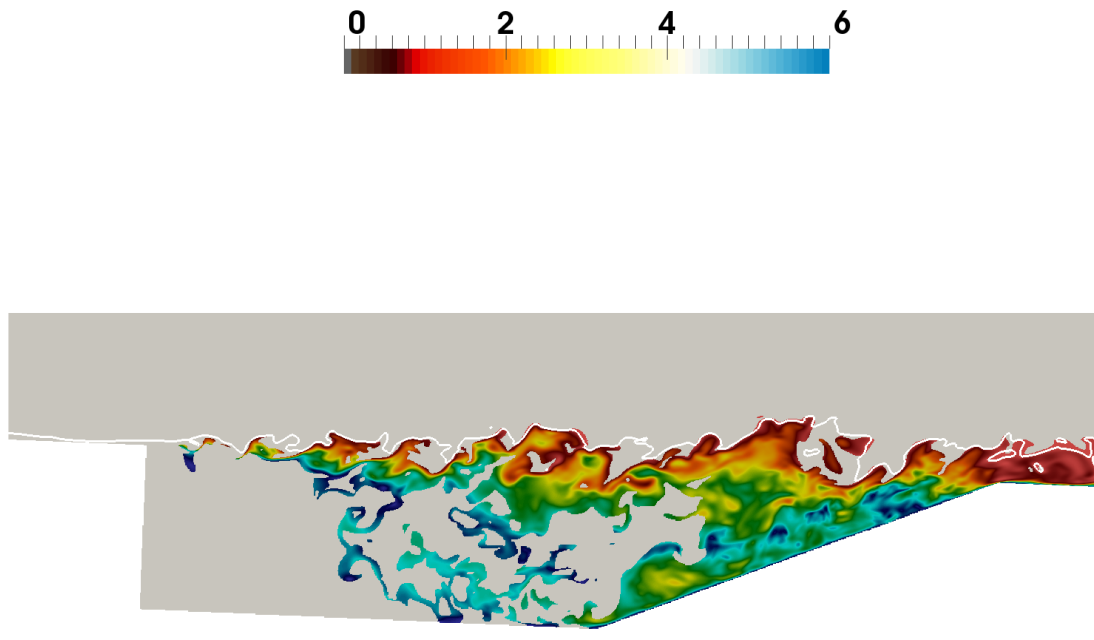

Mach number

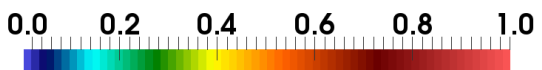

Figure 16: Instantaneous fields of (top) Heat release rate and (bottom) Mach number for fine mesh. Cells with heat release rate lower than $1 \%$ of maximum heat release are not shown. The white line represents iso-Mach $=1$. 


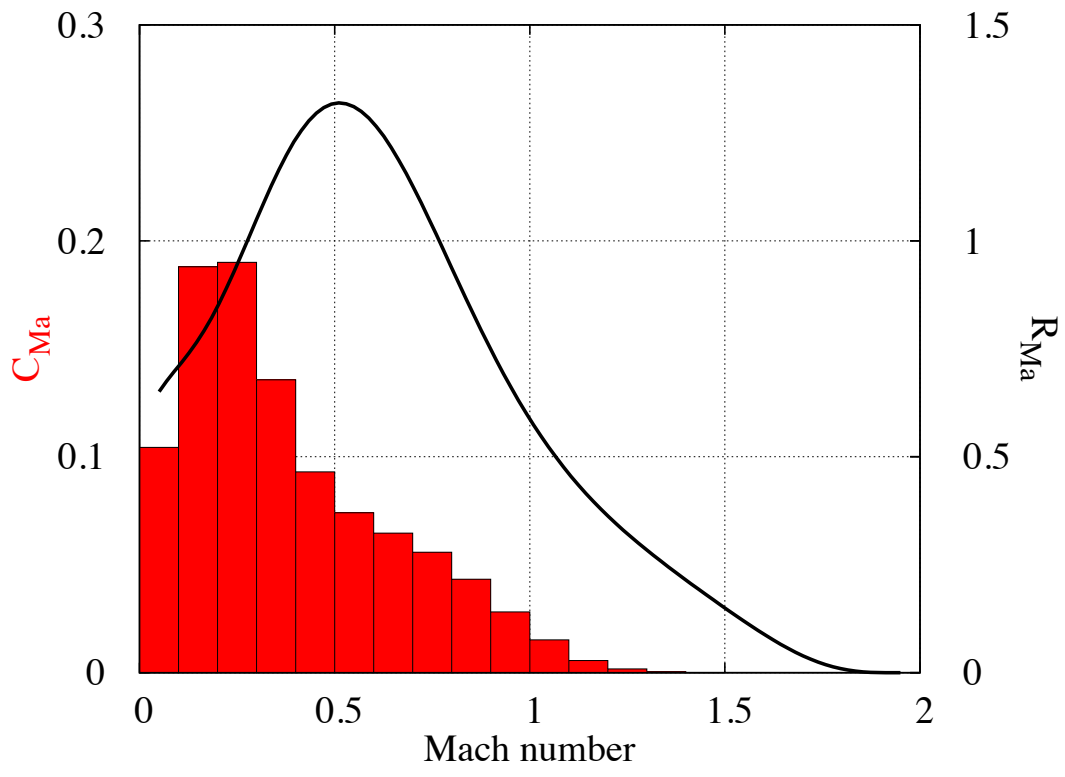

Figure 17: Dimensionless conditional mean of the heat release on Mach number $R_{M a}$ (curve), and percentage of cells contributing to the statistics in each interval (0.1) of Mach number $C_{M a}$ (histogram): fine mesh.
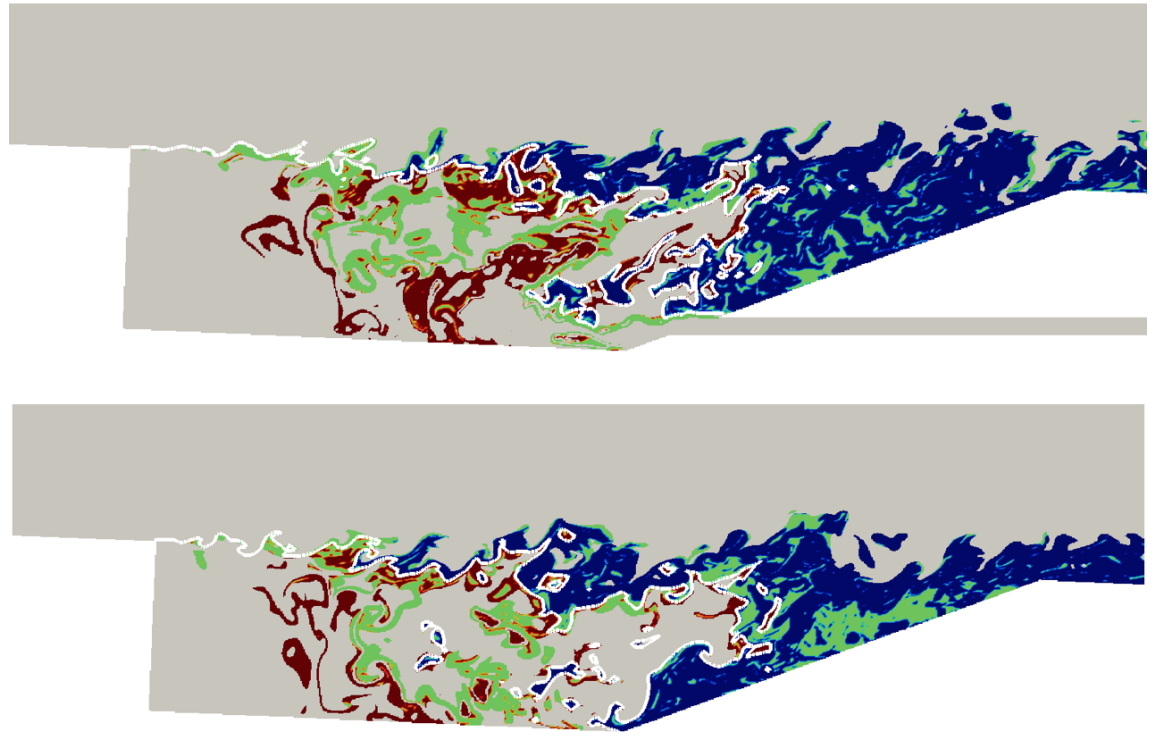

Flame Index

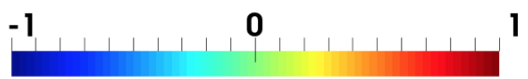

Figure 18: Distribution of flame index inside the cavity for injector centerplane (top) and centerplane between two injectors (bottom). -1: lean premixed, 0: nonpremixed, 1: rich premixed. The isoline $Z=Z_{s t}$ is displayed with a white line. Refined mesh. 


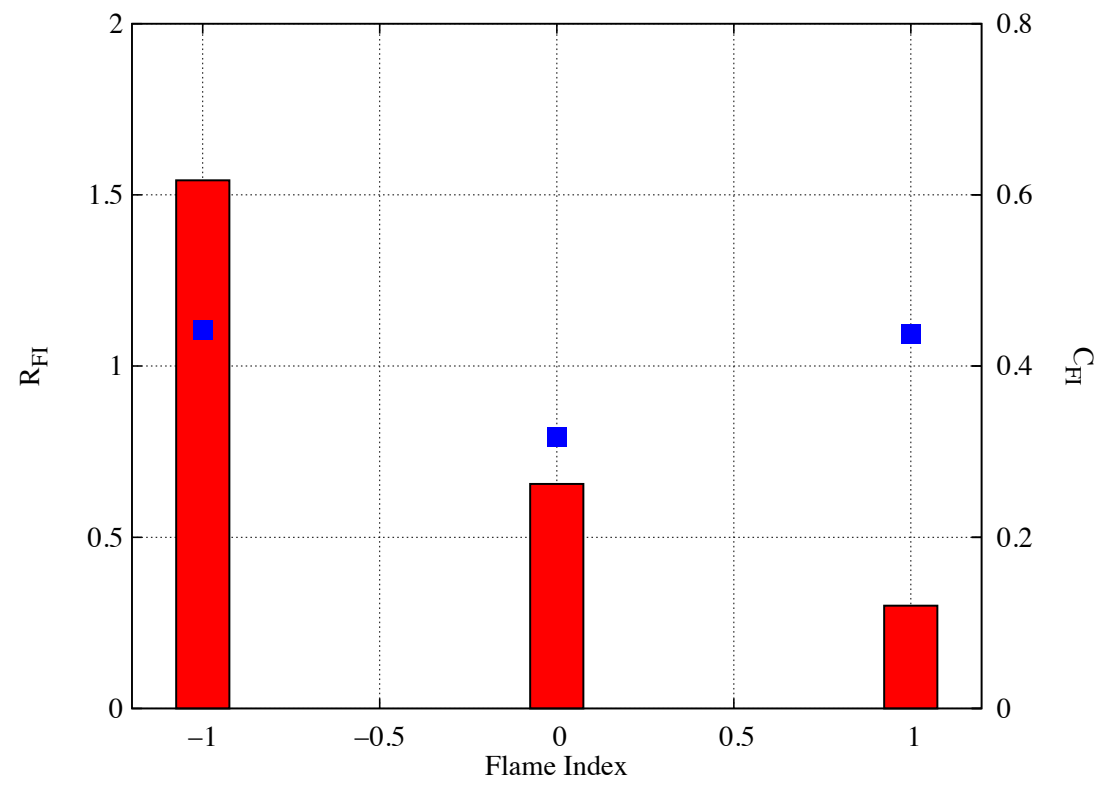

Figure 19: Dimensionless conditional mean of heat release by flame index $R_{F I}$ (squares), and contribution of each value of flame index to the heat release $C_{F I}$ (histogram).

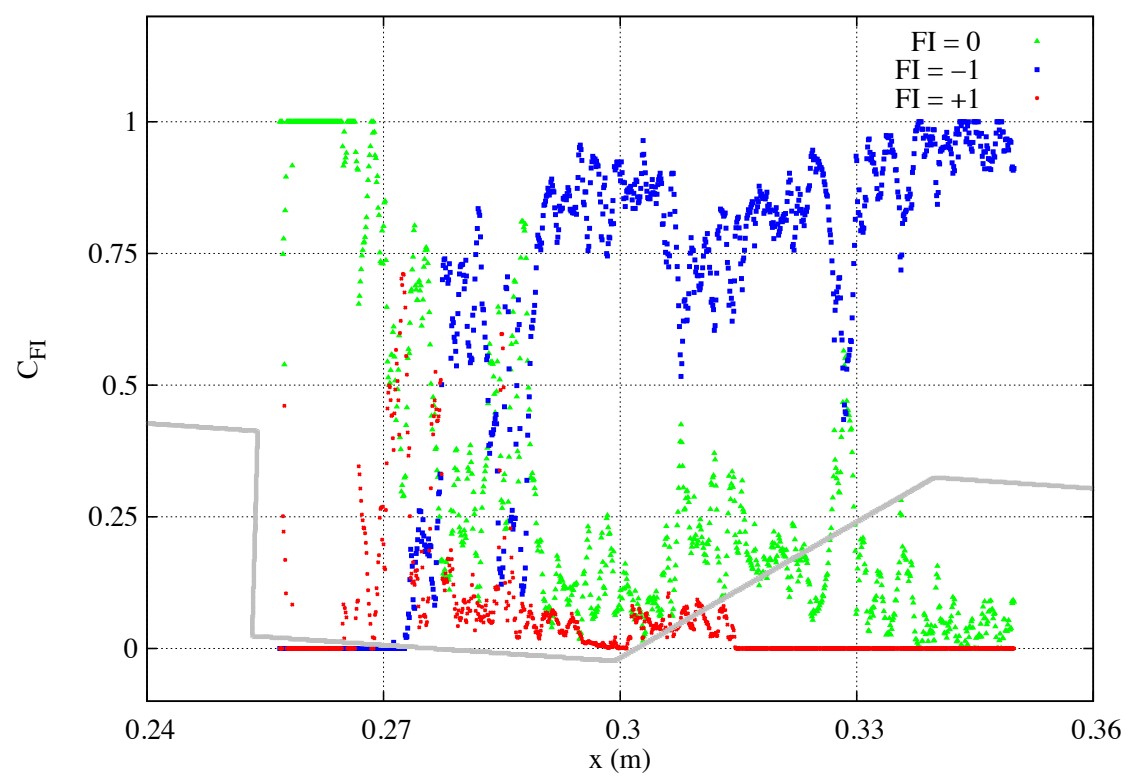

Figure 20: Partial contribution to the heat release $C_{F I}$ along $\mathrm{x}$ for $F I=-1,0$ or 1 . The gray line represents the cavity geometry. 

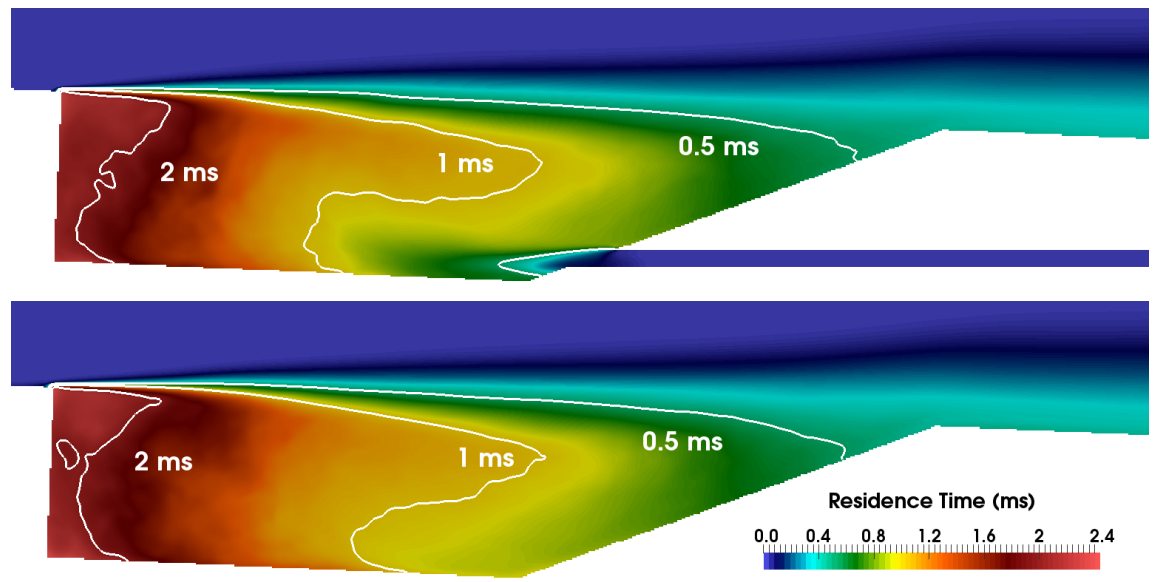

Figure 21: Averaged residence time inside the cavity in the injector centerplane (top) and the centerplane between two injectors (bottom). Isolines are displayed with white lines (coarse mesh).

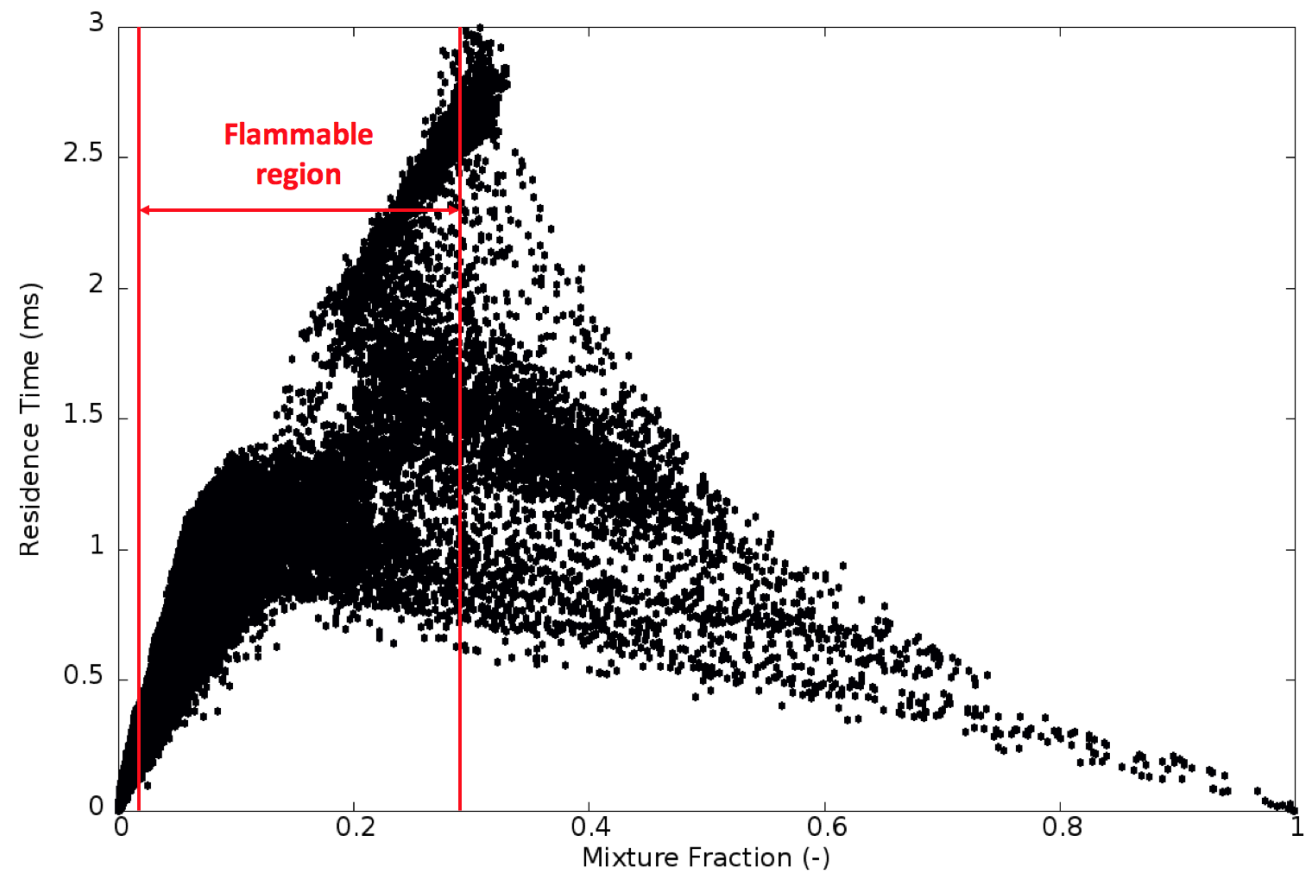

Figure 22: Scatter plot of residence time vs. mixture fraction. Only $1 \%$ of points are shown. The flammability limits of ethylene are shown with red lines (coarse mesh). 


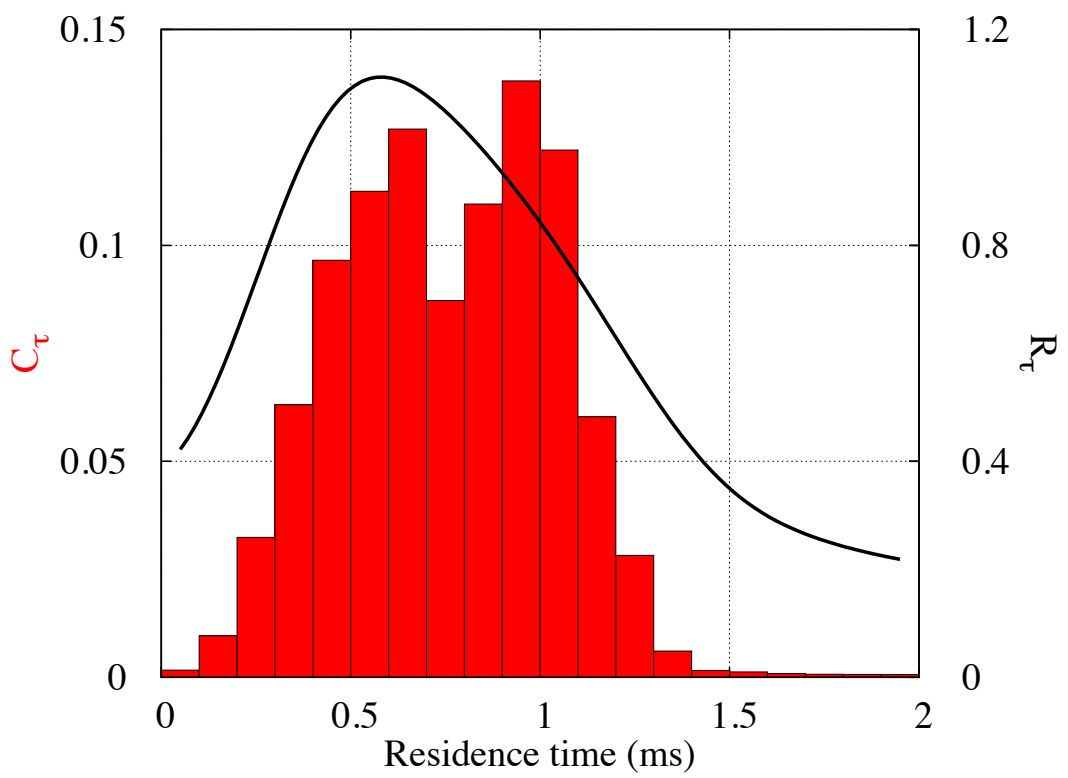

Figure 23: Dimensionless conditional mean of the heat release on residence time $R_{\tau}$ (curve), and percentage of cells contributing to the statistics in each interval $(0.1 \mathrm{~ms})$ of residence time $C_{\tau}$ (histogram). Coarse mesh. 